\title{
Comparative transcriptome profiling analyses during the lag phase uncover YAP1, PDR1, PDR3, $R P N 4$, and HSF1 as key regulatory genes in genomic adaptation to the lignocellulose derived inhibitor HMF for Saccharomyces cerevisiae
}

\author{
Menggen Ma, Z Lewis Liu*
}

\begin{abstract}
Background: The yeast Saccharomyces cerevisiae is able to adapt and in situ detoxify lignocellulose derived inhibitors such as furfural and HMF. The length of lag phase for cell growth in response to the inhibitor challenge has been used to measure tolerance of strain performance. Mechanisms of yeast tolerance at the genome level remain unknown. Using systems biology approach, this study investigated comparative transcriptome profiling, metabolic profiling, cell growth response, and gene regulatory interactions of yeast strains and selective gene deletion mutations in response to HMF challenges during the lag phase of growth.
\end{abstract}

Results: We identified 365 candidate genes and found at least 3 significant components involving some of these genes that enable yeast adaptation and tolerance to HMF in yeast. First, functional enzyme coding genes such as $A R I 1, A D H 6, A D H 7$, and OYE3, as well as gene interactions involved in the biotransformation and inhibitor detoxification were the direct driving force to reduce HMF damages in cells. Expressions of these genes were regulated by YAP1 and its closely related regulons. Second, a large number of PDR genes, mainly regulated by $P D R 1$ and PDR3, were induced during the lag phase and the PDR gene family-centered functions, including specific and multiple functions involving cellular transport such as TPO1, TPO4, RSB1, PDR5, PDR15, YOR1, and SNQ2, promoted cellular adaptation and survival in order to cope with the inhibitor stress. Third, expressed genes involving degradation of damaged proteins and protein modifications such as SHP1 and SSA4, regulated by RPN4, HSF1, and other co-regulators, were necessary for yeast cells to survive and adapt the HMF stress. A deletion mutation strain $\Delta p n 4$ was unable to recover the growth in the presence of HMF.

Conclusions: Complex gene interactions and regulatory networks as well as co-regulations exist in yeast adaptation and tolerance to the lignocellulose derived inhibitor HMF. Both induced and repressed genes involving diversified functional categories are accountable for adaptation and energy rebalancing in yeast to survive and adapt the HMF stress during the lag phase of growth. Transcription factor genes YAP1, PDR1, PDR3, RPN4, and HSF1 appeared to play key regulatory rules for global adaptation in the yeast $S$. cerevisiae.

\section{Background}

Bioethanol production from lignocellulosic biomass including agricultural and forestry residues has attracted increased attention worldwide [1-8]. Lignocellulosic

\footnotetext{
* Correspondence: zlewis.liu@ars.usda.gov

* Correspondence: zlewis.liu@ars.usda.gov USDA-ARS, Peoria, IL USA
}

(c) 2010 Ma and Liu; licensee BioMed Central Ltd. This is an Open Access article distributed under the terms of the Creative Commons Attribution License (http://creativecommons.org/licenses/by/2.0), which permits unrestricted use, distribution, and reproduction in any medium, provided the original work is properly cited. biomass needs to be depolymerized into simple sugars in order to be utilized for microbial fermentation. The commonly applied dilute acid pretreatment generates numerous chemical byproducts that inhibit cell growth and interfere with subsequent microbial fermentation [5,9-11]. Among numerous inhibitory compounds, furfural and 5-hydroxymethylfurfural (HMF) are commonly encountered inhibitors [9,12-14]. Furfural and HMF are 
formed by dehydration of pentoses and hexoses released from hemicellulose and cellulose, respectively $[15,16]$. These inhibitors can damage cell structures, inhibit cell growth, reduce enzymatic activities, generate cellular reactive oxygen species (ROS), break down DNA, and inhibit protein and RNA synthesis [14,17-20]. The presence of fermentation inhibitors represents a bottle neck in cellulosic ethanol conversion technology and overcoming the inhibitor effect is one of the fundamental challenges to the industrial production of bioethanol from lignocellulosic biomass.

Furfural and its conversion product have been widely studied while knowledge of HMF conversion is limited due to a lack of commercial source of its conversion product $[5,14,15,21-23]$. Unlike evaporative furfural, HMF is more stable and difficult to degrade in cell culture. Recently, an HMF metabolic conversion product was isolated and identified as 2, 5-bis-hydroxymethylfuran (Furan-2,5-dimethanol, FDM) [24]. A dosedependent response of yeast to HMF was demonstrated and a lag phase was used to measure levels of strain tolerance $[24,25]$. The yeast Saccharomyces cerevisiae is able to in situ detoxify HMF into the less toxic compound FDM through NADPH-dependent reductions $[24,26,27]$. Typically, yeast strains show a lag of delayed cell growth after inhibitor challenge such as with furfural and HMF, under sublethal doses. Once HMF and furfural inhibitor levels were chemically reduced to a certain lower concentration, cell growth recovered and the glucose-to-ethanol conversion accelerated at a faster rate than would normally occur [24]. It was suggested that genomic adaptation occurred during the lag phase $[23,28]$. In fact, inhibitor-tolerant yeast strains showed significant shorter lag phases under the inhibitor challenges compared with a wild type strain $[28,29]$. Gene expressions of selected pathways of the tolerant yeast are distinct from the wild type control [29]. Sequence mutations are common and a large number of single nucleotide polymorphism (SNP) mutations were observed throughout all 16 chromosomes for a tolerant yeast strain (Liu et al, unpublished data; $\mathrm{Xu}$, personal communication 2010). Adaptations appear to occur at the genome level. However, little is known about gene expression response and regulatory events for yeast during the adaptation lag phase. The objective of this study was to characterize transcriptome response of yeast during the lag phase after the HMF challenge. Using a comparative time course study, we investigated the dynamics of transcriptome profiling during this critical stage applying DNA microarray assays and regulatory analysis. Important genes, together with transcription factors (TFs) involved in the HMF stress response, were identified. The functions of selective candidate genes were verified by corresponding gene deletion mutation strains. Significant regulatory interaction networks were uncovered during the genome adaptation in yeast. Results of this study provide insight into mechanisms of yeast adaptation and tolerance to lignocellulose derived inhibitors. This will directly aid engineering efforts for more tolerant strain development.

\section{Results}

\section{Cell growth response and metabolic conversion profiles}

Compared to a non-treated control, yeast challenged by HMF displayed a significant drop in cell growth as measured by $\mathrm{OD}_{600}$ absorbance $2 \mathrm{~h}$ after the treatment (Figure 1A). Although the cell growth was recovered at a later time, cell density of the HMF-treated yeast was relatively low throughout the course of the study. Similarly, glucose consumption for the HMF-treated culture was slower and glucose was depleted at $16 \mathrm{~h}$, approximately $4 \mathrm{~h}$ later than the non-treated control (Figure 1B). As expected, HMF was undetectable and FDM was detected as HMF conversion product [24] in HMFtreated cultures less than $24 \mathrm{~h}$ after incubation (Figure 1C). No HMF or FDM was detected from the control culture.

\section{Transcription expression dynamics during the lag phase}

Clustering analysis distinguished significant differences for expression responses by HMF between the treated and untreated conditions over time (data not shown). Among the more than 6,000 genes of the yeast genome, 365 genes were identified as differentially expressed by ANOVA for at least 2-fold changes during the lag phase of 10 to $120 \mathrm{~min}$ by the HMF challenge (Figure 2, Additional file 1). Among these, 71 genes were induced constantly throughout the lag phase while 246 genes were repressed at various stages of the lag phase (Figure 2, Table 1). Many of the induced genes showed immediate enhanced expressions within $10 \mathrm{~min}$ after the HMF challenge. These genes mainly fall with functional categories of reductase, pleiotropic drug resistance (PDR), proteasome and ubiquitin, amino acids metabolism, stress response functions, and others (Table 1 and 2). For example, $A D H 7$, encoding NADPH-dependent medium chain alcohol dehydrogenase displayed the highest induction of more than 30-fold increase in mRNA abundance at $10 \mathrm{~min}$ after the HMF treatment. Other significantly induced genes including ARI1, GRE2, PDR5, RSB1, PUT1, CHA1, HSP26, SSA4, and OYE3, which showed more than 10 -fold mRNA increase at various times during the lag phase.

The repressed genes are mainly involved in the functional categories of ribosome biogenesis, amino acid and derivative metabolic process, RNA metabolic process, transport, and others (Figure 3, Additional file 2). Most of the genes encoding enzymes for arginine biosynthesis 


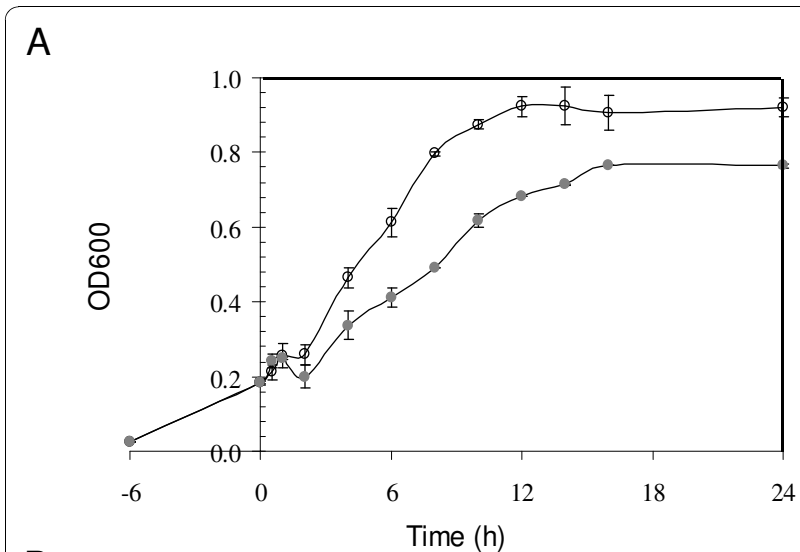

B

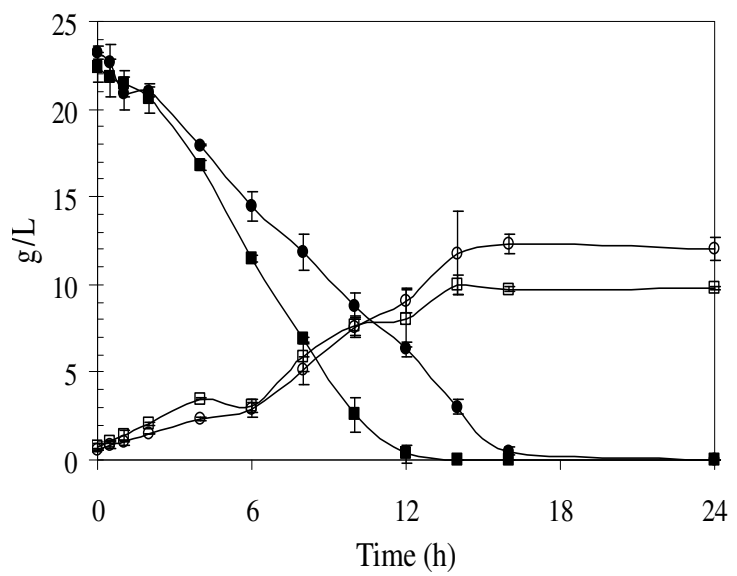

C

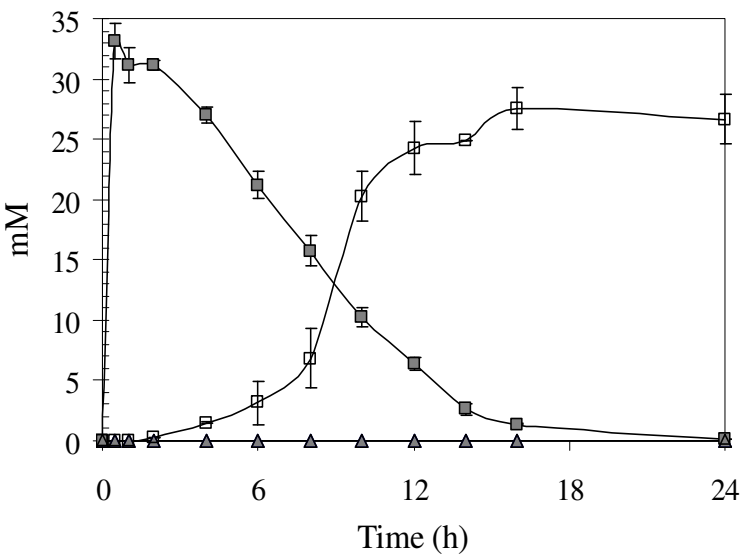

Figure 1 Yeast growth and metabolic profile response to HMF. Comparisons of cell growth and metabolic profiles of Saccharomyces cerevisiae NRRL Y-12632 between an HMF treatment $(30 \mathrm{mM})$ and an untreated condition. A. Cell growth as measured by $\mathrm{OD}_{600}$ for HMF treated condition (grey circle) and control (open circle). B. Glucose consumption (filled circle) and ethanol conversion (open circle) for HMF treated condition versus glucose (filled square) and ethanol (open square) for control. C. HMF (grey square) and its conversion product furandimethanol (FDM) (open square) for HMF treated condition versus HMF (grey triangle) and FDM (open triangle) for the control. were severely repressed, such as ARG1, ARG3, ARG4, $A R G 5,6, A R G 7$, and ARG8 (Additional file 1). For the repressed genes, three types of dynamic responses were observed. A small group of two dozen genes showed transient inductions at 10 min but quickly turned into repressed after $30 \mathrm{~min}$, such as PCL6 and PCL8 for glycogen metabolism, MAL1, MAL11, and MPH3 for maltose utilization. Another group of about 30 genes were constantly repressed, and these were mainly in the functional categories of amino acid metabolism, such as ARG1, ARG3, ARG4, ARG5,6, ARG7 for arginine metabolism, HIS1, HIS3, and HIS4 for histidine metabolism, ARO3, ARO4, HOM2, and HOM3 for aromatic amino acid metabolism. The third group of the repressed genes were initially repressed at 10 or $30 \mathrm{~min}$ but recovered at later time points. This group of repressed genes fall within the categories of rRNA processing, tRNA export, and ribosomal biogenesis such as NOB1, PUS1, RRP5, NOP56, and CBF5; mitochondrial mRNA maturase such as $B I 2$ and BI3; vitamin B6 biosynthesis gene $S N Z 1$; and telomere length maintenance gene YKU80 (Additional file 1).

\section{Relevant transcription factors}

Under the HMF challenge, we found that seven transcription factor genes, PDR1, PDR3, YAP1, YAP5, YAP6, $R P N 4$, and HSF1, displayed significant greater expression during the lag phase in response to the HMF challenge (Figure 4). Except for HSF1, most transcription factor genes displayed greater than 2-fold increase after the HMF treatment. By the aid of T-profiler [30], YEASTRACT database [31] and interactive pathway analysis using GeneSpring GX 10.0, we identified these genes as the most important transcription factor genes positively regulating gene expression response in adaptation to the HMF stress during the lag phase in yeast.

We further analyzed protein binding motifs for these genes and found each transcription factor gene harbored protein binding motifs for Pdr1p, Pdr3p, Yap1p, Yap5p, Yap6p, Rpn4p, and Hsf1p. DNA binding motifs of Pdr1/ $3 \mathrm{p}$ were found in promoter regions of PDR3, YAP5, $P D R 6$, and RPN4; Yap1p binding sites in all six transcription factor genes except for PDR1; and Hsf1p sites in all six genes except for PDR1 (Figure 5). Except for PDR1 which had a single Yap1p binding site, each of the other six transcription factor genes displayed multiple binding sites for multiple transcription factors. For example, RPN4 had 13 binding sites of 4 transcription factors, and PDR3 had 6 sites for 2. Interactions involving multiple transcription factors apparently exist. For example, highly expressed RPN4 in this study was found to be regulated by Yap1p, Pdr1p, Pdr3p, and Hsf1p that 


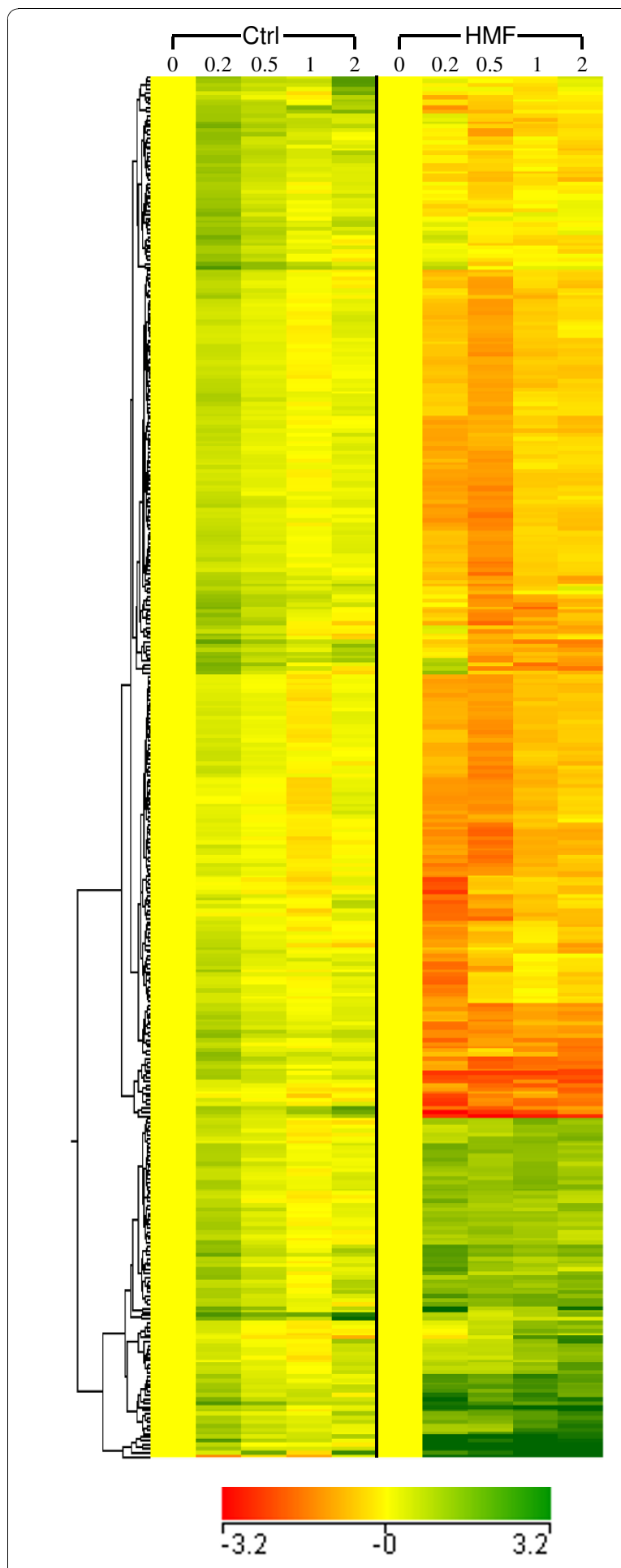

Figure 2 Transcriptome response to HMF during the lag phase Hierarchical clustering of genes showing significant differential expression under HMF stress and displaying a 2-fold change for at least one time point compared with $0 \mathrm{~h}$ during the lag phase. Scales of the expression are indicated by an integrated color bar at the bottom. supported by ChIP-chip data and microarray assay of transcription factor mutations [32-37]. On the other hand, it also demonstrated positive feedback to its regulators of Yap1p and Pdr1p [33,37,38]. The presence of DNA binding motifs of a transcription factors' own in its promoter region, such as PDR3, YAP1, and HSF1 (Figure 5), suggested a self-regulated expression. The highly induced expression of the seven transcription factor genes in response to the HMF challenge and multiple protein binding motifs across the transcription factors suggested co-regulation and interactions of multiple transcription factors under the stress. As for many repressed expression responses to HMF, we identified five transcription factor genes ARG80, ARG81, GCN4, $F H L 1$, and RAP1 that displayed down-regulated expressions (Additional file 3).

\section{YAP1 regulated gene expression networks}

Among the seven transcription factor genes, YAP1 displayed consistently higher inductions, a 2- to 3-fold increase during the lag phase (Figure 4). Yap1p acts as a sensor for oxidative molecules, and activates the transcription response of anti-oxidant genes by recognizing Yap1p response elements (YRE), 5'-TKACTMA-3', in the promoter region $[33,39,40]$.

A total of 41 HMF-induced genes were found to have the YRE sequence in their promoter region (Additional file 4). Many genes were confirmed to be regulated directly by YAP1 or indirectly through YAP5 and YAP6 (Figure 6). Most YAP1-regulated genes were classified in the functional categories of redox metabolism, amino acid metabolism, stress response, DNA repair, and others (Table 2). For example, the highly induced oxidoreductase genes $A D H 7, G R E 2$, and OYE3 were found as regulons of YAP1 (Figure 6) [32,38,41]. ADH7 and GRE2 were also co-regulated by Yap5p and Yap6p $[33,36]$. These two genes were among those confirmed as reductases actively involved in the HMF detoxification [26]. ARI1, a recently characterized aldehyde reductase contributing to detoxification of furfural and HMF [27], was found to be regulated by Yap6p [33] which is a regulon of YAP1. In addition, YAP1 and other YAP gene family members were shown to co-regulate numerous genes in a wide range of functional categories such as PDR, heat shock protein, chaperones, amino acid metabolism, as well as other regulators.

The significance of the role of the YAP gene family in adaptation and tolerance to HMF is confirmed by growth responses of the deletion mutations. Single YAP gene deletion mutations were able to grow normally without HMF treatment (Figure 7A). However, in the presence of $15 \mathrm{mM} \mathrm{HMF}$, mutations $\Delta$ yap 1, Dyap4, 
$\Delta y a p 5$, and $\Delta y a p 6$ showed delayed growth compared with their parental strain (Figure 7B). Among these, $\triangle y a p 1$ displayed a 4-day long lag phase, indicating a profound functional defect affected by the YAP1 gene.

\section{PDR family and PDR1/3 involved regulatory interactions}

Among the significantly induced genes by HMF, at least 15 genes were categorized into the PDR family (Table 1). Many genes displayed consistent induced expressions ranging from 3 - to 30 -fold increases during the lag phase (Table 1). Gene products of these increased transcripts were in the protein categories of drug/toxin transport for TPO1 and TPO4, Transport ATPase for $R S B 1$, and $A B C$ transporters for PDR15 (Table 3). SNQ2, YOR1, PDR5, and PDR12 encoding proteins shared functions of all these three categories. In addition, many PDR proteins have functions such as ATP binding and chemical agent resistance (Table 3). Most of these genes have the pleiotropic drug response element (PDRE) in their promoter regions (Additional file 4).

HMF-induced transcription factor genes $P D R 1$ and $P D R 3$ regulate gene expression under a large variety of unrelated chemical stress conditions by binding to the PDRE of target genes [42-45]. Both Pdr1p and Pdr3p recognize CGG triplets oriented in opposite directions (CCGCGG) to form an inverted repeat [46], and able to form homodimers or heterodimers to activate target gene expression [42]. Many induced genes regulated by Pdr1p and/or Pdr3p in this group are involved in export of both xenobiotic compounds and endogenous toxic metabolites using ATP-binding cassette (ABC) transporters (Pdr5p, Pdr15p, Snq2p, and Yor1p), lipid composition of the plasma membrane (Rsb1p and Ict1p), export of polyamines by polyamine transporters (Tpolp and Tpo4p), DNA repairing (Mag1p and Ddilp), and other functions (Figure 6) [37,47-52]. At least eight genes induced by HMF in this study were regulated by both Pdr1p and Pdr3p. Pdr1p and Pdr3p also recognize and activate other subsets of genes. Pdr3p participates in certain processes that do not involve Pdr1p, such as regulating DNA damage-inducible genes MAG1 and DDI1 [53]. Similarly, some genes are only regulated by Pdr1p, such as RSB1 [54], $A D H 7$, and PRE3 [32,33]. We also found that the PDR3 promoter contains two PDREs that can be autoregulated by itself in addition to being a regulon of Pdr1p [50,55]. PDR1 and PDR3 also demonstrated regulatory connections with a broad range of functional category genes as well as most active regulatory genes.

PDR 1 and PDR3 gene deletion mutations were assayed to confirm their influence on the expression of the potential regulons. When examined by qRT-PCR, mutant $\Delta p d r 1$ displayed reduced transcriptional abundance for many genes, such as PDR5, PDR10, PDR15, YOR1, SNQ2, ICT1, GRE2, TPO1, YMR102C, and YGR035C compared with its parental strain BY4742 $2 \mathrm{~h}$ after exposure to furfural and HMF (Figure 8A). The mutation $\Delta p d r 3$ appeared to have a similar regulatory effect but to a lesser degree and to fewer genes (Figure 8B). However, it was clear that expression of $P G A 3$ was affected by $\Delta p d r 3$ but not $\Delta p d r 1$.

\section{Regulatory interactions of RPN4 and HSF1}

Among the genes induced by HMF, at least 14 ubiquitin-related and proteasome genes for protein degradation were identified (Figure 6). These genes, by encoding enzymes involving in the degradation of damaged proteins, maintain cell viability and functions under the inhibitor stress. The induction of these genes was predicted to be under the control of the transcription factor Rpn4p by binding to the proteasome-associated control element (PACE, 5'- GGTGGCAAA-3') [56], and the PACE was found in the promoter of most ubiquitin-related and proteasome genes induced by HMF (Additional file 4). In this study, RPN4 was continuously enhanced over time during the lag phase (Figure 4, Table 1). Rpn4p levels are regulated by the $26 \mathrm{~S}$ proteasome via a negative feedback control mechanism [57]. It is also required for regulation of genes involved in DNA repair and other cellular processes, such as DNA damage-inducible genes MAG1 and DDI1 [33,53]. Interestingly, Rpn4p is a feedback regulator of YAP1 and PDR1 [37]. The consistent expression of RPN4 and its known complex functions including regulatory functions indicated a significant role of this transcription factor gene in regulating genomic adaptation networks during the lag phase. This was further demonstrated by the comparative performance of the deletion mutation response to HMF. While it was able to grow and establish a culture normally without HMF challenge, the strain harboring $\Delta r p n 4$ failed to recover in the presence of 15 mM HMF 6 days after incubation (Figure 7A and $7 \mathrm{~B})$.

Although the levels of induction of HSF1 were not as great as RPN4, we found its constantly enhanced expression response to HMF was statistically significant. Upregulated genes HSP26 and SSA4 for protein folding and refolding in this study have been reported to be regulated by Hsf1p [33,58]. It was also a positive regulator of other transcription factor genes RPN4, PDR3, YAP5, and YAP6 [32-34,36]. HSF1 is likely involved in the complex co-regulation networks to the HMF stress.

\section{Regulatory interactions of repressed genes}

For 246 significantly repressed genes, we found at least 5 important regulatory genes were involved in the down-regulated expression. For example, ARG1, ARG3, 
Table 1 Significantly induced genes of Saccharomyces cerevisiae by HMF during the lag phase

\begin{tabular}{|c|c|c|c|c|c|c|}
\hline \multirow{2}{*}{$\begin{array}{l}\text { Systematic } \\
\text { Name }\end{array}$} & \multirow{2}{*}{$\begin{array}{l}\text { Standard } \\
\text { Name }\end{array}$} & \multirow[t]{2}{*}{ Description } & \multicolumn{4}{|c|}{ Fold change } \\
\hline & & & $0.2 \mathrm{~h}$ & $0.5 \mathrm{~h}$ & $1 \mathrm{~h}$ & $2 \mathrm{~h}$ \\
\hline \multicolumn{7}{|l|}{ Reductase } \\
\hline YCR105W & ADH7 & NADPH-dependent medium chain alcohol dehydrogenase with broad substrate specificity & +38.4 & +60.3 & +81.3 & +39.5 \\
\hline YGL157W & $A R / 1$ & NADPH-dependent aldehyde reductase & +12.3 & +21.3 & +29.2 & +27.2 \\
\hline YOL151W & GRE2 & $\begin{array}{l}\text { 3-methylbutanal reductase and NADPH-dependent methylglyoxal reductase (D- } \\
\text { lactaldehyde dehydrogenase) }\end{array}$ & +8.0 & +7.6 & +10.4 & +12.0 \\
\hline YOR374W & ALD4 & NAD(P)-dependent mitochondrial aldehyde dehydrogenase & +4.3 & +3.2 & +2.7 & +3.2 \\
\hline \multicolumn{7}{|l|}{ PDR family } \\
\hline YOR153W & PDR5 & Plasma membrane ATP-binding cassette (ABC) transporter & +30.0 & +19.0 & +30.6 & +23.7 \\
\hline YPL058C & PDR12 & Plasma membrane ATP-binding cassette (ABC) transporter & +7.1 & +4.1 & +6.2 & +3.3 \\
\hline YDR406W & PDR15 & Plasma membrane ATP binding cassette $(A B C)$ transporter & +9.5 & +3.5 & +5.4 & +7.3 \\
\hline YDR011W & SNQ2 & Plasma membrane ATP-binding cassette (ABC) transporter & +4.7 & +3.8 & +6.4 & +4.1 \\
\hline YGR281W & YOR1 & Plasma membrane ATP-binding cassette (ABC) transporter & +4.7 & +3.0 & +4.4 & +3.5 \\
\hline YOR049C & RSB1 & Suppressor of sphingoid long chain base (LCB) sensitivity of an LCB-lyase mutation & +15.7 & +6.9 & +9.5 & +8.6 \\
\hline YLR099C & ICT1 & Lysophosphatidic acid acyltransferase & +3.4 & +2.9 & +4.8 & +6.2 \\
\hline YER142C & MAG1 & 3-methyl-adenine DNA glycosylase involved in protecting DNA against alkylating agents & +4.3 & +4.5 & +5.1 & +3.7 \\
\hline YER143W & DD/1 & DNA damage-inducible v-SNARE binding protein & +2.4 & +2.2 & +2.4 & +1.7 \\
\hline YLL028W & TPO1 & Polyamine transporter that recognizes spermine, putrescine, and spermidine & +4.5 & +3.3 & +5.1 & +4.3 \\
\hline YOR273C & TPO4 & Polyamine transporter that recognizes spermine, putrescine, and spermidine & +2.7 & +2.0 & +3.0 & +2.6 \\
\hline YDL020C & RPN4 & Transcription factor that stimulates expression of proteasome genes & +1.9 & +2.5 & +2.8 & +3.3 \\
\hline YGR035C & YGR035C & Putative protein of unknown function & +3.1 & +3.8 & +4.1 & +5.9 \\
\hline YLL056C & YLL056C & Putative protein of unknown function & +2.0 & +2.0 & +5.8 & +6.2 \\
\hline YMR102C & YMR102C & Putative protein of unknown function & +1.8 & +1.6 & +2.2 & +2.9 \\
\hline \multicolumn{7}{|c|}{ Proteasome and ubiquitin } \\
\hline YER012W & PRE1 & Beta 4 subunit of the $20 \mathrm{~S}$ proteasome & +2.7 & +2.4 & +2.1 & +1.8 \\
\hline YJL001W & PRE3 & Beta 1 subunit of the $20 \mathrm{~S}$ proteasome & +3.0 & +3.0 & +2.6 & +2.1 \\
\hline YOL038W & PRE6 & Alpha 4 subunit of the $20 \mathrm{~S}$ proteasome & +2.0 & +2.2 & +2.8 & +2.3 \\
\hline YBL041W & PRE7 & Beta 6 subunit of the $20 \mathrm{~S}$ proteasome & +3.5 & +2.6 & +2.6 & +1.9 \\
\hline YOR362C & PRE10 & Alpha 7 subunit of the $20 \mathrm{~S}$ proteasome & +2.4 & +2.2 & +2.2 & +1.9 \\
\hline YER094C & PUP3 & Beta 3 subunit of the $20 \mathrm{~S}$ proteasome involved in ubiquitin-dependent catabolism & +2.4 & +2.2 & +2.9 & +2.1 \\
\hline YDR427W & RPN9 & Non-ATPase regulatory subunit of the $26 \mathrm{~S}$ proteasome & +2.7 & +2.4 & +2.4 & +2.1 \\
\hline YFR052W & RPN12 & Subunit of the $19 \mathrm{~S}$ regulatory particle of the $26 \mathrm{~S}$ proteasome lid & +2.8 & +2.4 & +2.6 & +2.5 \\
\hline YHL030W & ECM29 & Major component of the proteasome & +4.6 & +3.3 & +3.6 & +2.6 \\
\hline YDL007W & RPT2 & $\begin{array}{l}\text { One of six ATPases of the } 19 \mathrm{~S} \text { regulatory particle of the } 26 \mathrm{~S} \text { proteasome involved in the } \\
\text { degradation of ubiquitinated substrates }\end{array}$ & +3.3 & +2.6 & +2.6 & +2.4 \\
\hline YDR394W & RPT3 & $\begin{array}{l}\text { One of six ATPases of the } 19 \mathrm{~S} \text { regulatory particle of the } 26 \mathrm{~S} \text { proteasome involved in the } \\
\text { degradation of ubiquitinated substrates }\end{array}$ & +2.9 & +2.0 & +2.5 & +2.5 \\
\hline YOR259C & RPT4 & $\begin{array}{l}\text { One of six ATPases of the } 19 \mathrm{~S} \text { regulatory particle of the } 26 \mathrm{~S} \text { proteasome involved in the } \\
\text { degradation of ubiquitinated substrates }\end{array}$ & +3.1 & +2.6 & +3.2 & +2.5 \\
\hline YBL058W & SHP1 & $\begin{array}{l}\text { UBX (ubiquitin regulatory } X \text { ) domain-containing protein that regulates Glc7p phosphatase } \\
\text { activity and interacts with Cdc48p }\end{array}$ & +2.5 & +2.0 & +2.1 & +2.8 \\
\hline YFL044C & OTU1 & Deubiquitylation enzyme that binds to the chaperone-ATPase Cdc48p & +2.3 & +1.9 & +3.3 & +2.3 \\
\hline \multicolumn{7}{|l|}{ Amino acids } \\
\hline YLR142W & PUT1 & Proline oxidase & +4.8 & +6.9 & +10.8 & +43.0 \\
\hline YHR037W & PUT2 & Delta-1-pyrroline-5-carboxylate dehydrogenase & +3.7 & +3.7 & +4.7 & +3.3 \\
\hline YJR010W & MET3 & ATP sulfurylase & +2.5 & +2.7 & +3.3 & +3.6 \\
\hline YKL001C & MET14 & Adenylylsulfate kinase & +1.7 & +2.6 & +2.8 & +3.2 \\
\hline YCL064C & CHAl & $\begin{array}{l}\text { Catabolic L-serine (L-threonine) deaminase, catalyzes the degradation of both L-serine and } \\
\text { L-threonine }\end{array}$ & +13.3 & +17.7 & +15.8 & +7.3 \\
\hline YLR089C & ALT1 & Alanine transaminase & +2.9 & +3.1 & +4.1 & +4.9 \\
\hline YPL111W & CAR1 & Arginase, responsible for arginine degradation & +3.4 & +2.2 & +1.9 & +1.6 \\
\hline
\end{tabular}


Table 1 Significantly induced genes of Saccharomyces cerevisiae by HMF during the lag phase (Continued)

\begin{tabular}{|c|c|c|c|c|c|c|}
\hline \multicolumn{7}{|l|}{ Stress } \\
\hline YBR072W & HSP26 & Small heat shock protein (SHSP) with chaperone activity & +10.8 & +1.8 & +2.0 & +8.0 \\
\hline YER103W & SSA4 & Heat shock protein that is highly induced upon stress & +13.2 & +1.5 & +2.0 & +2.6 \\
\hline \multicolumn{7}{|c|}{ Transcription factors } \\
\hline YML007W & YAP1 & Basic leucine zipper (bZIP) transcription factor required for oxidative stress tolerance & +3.3 & +2.1 & +2.5 & +2.2 \\
\hline YDL020C & RPN4 & Transcription factor that stimulates expression of proteasome genes & +1.9 & +2.5 & +2.8 & +3.3 \\
\hline \multicolumn{7}{|l|}{ Others } \\
\hline YPL171C & OYE3 & Conserved NADPH oxidoreductase containing flavin mononucleotide (FMN) & +5.9 & +3.9 & +5.3 & +17.7 \\
\hline YOR306C & MCH5 & Plasma membrane riboflavin transporter & +2.6 & +4.9 & +7.8 & +7.2 \\
\hline YAR073W & IMD1 & Nonfunctional protein with homology to IMP dehydrogenase & +2.2 & +2.1 & +3.4 & +2.7 \\
\hline YBL078C & ATG8 & Component of autophagosomes and Cvt vesicles & +4.5 & +3.3 & +2.7 & +3.5 \\
\hline YBR062C & YBR062C & Hypothetical protein & +2.5 & +2.4 & +2.4 & +2.1 \\
\hline YML130C & ERO1 & Thiol oxidase required for oxidative protein folding in the endoplasmic reticulum & +2.3 & +2.4 & +2.8 & +2.3 \\
\hline YBR114W & RAD16 & $\begin{array}{l}\text { Protein that recognizes and binds damaged DNA in an ATP-dependent manner (with } \\
\text { Rad7p) during nucleotide excision repair }\end{array}$ & +2.8 & +2.1 & +2.8 & +1.7 \\
\hline YBR170C & NPL4 & Endoplasmic reticulum and nuclear membrane protein & +2.4 & +2.7 & +2.2 & +1.5 \\
\hline YDL021W & GPM2 & Homolog of Gpm1p phosphoglycerate mutase & +3.5 & +1.6 & +1.7 & +2.8 \\
\hline YBL101W-A & YBL101W-A & Retrotransposon TYA Gag gene co-transcribed with TYB Pol & +1.4 & +1.6 & +2.6 & +6.4 \\
\hline YDR210W-B & YDR210W-B & Retrotransposon TYA Gag and TYB Pol genes & +1.9 & +1.7 & +2.6 & +4.4 \\
\hline YDR316W-B & YDR316W-B & Retrotransposon TYA Gag and TYB Pol genes & +1.8 & +1.8 & +2.6 & +3.2 \\
\hline YDR365W-B & YDR365W-B & Retrotransposon TYA Gag and TYB Pol genes & +1.7 & +1.7 & +2.2 & +4.3 \\
\hline YDR515W & SLF1 & RNA binding protein that associates with polysomes & +2.7 & +2.7 & +2.4 & +2.7 \\
\hline YOR009W & TIR4 & Cell wall mannoprotein of the Srp1p/Tip $1 p$ family of serine-alanine-rich proteins & -1.3 & +1.3 & +4.6 & +5.9 \\
\hline YPL156C & PRM4 & Pheromone-regulated protein proposed to be involved in mating & +3.4 & +2.8 & +3.5 & +3.5 \\
\hline YGL062W & PYC1 & Pyruvate carboxylase isoform & +2.3 & +2.6 & +3.1 & +2.1 \\
\hline YOR007C & SGT2 & Glutamine-rich cytoplasmic protein of unknown function & +2.8 & +2.5 & +2.9 & +3.0 \\
\hline YOR052C & YOR052C & Nuclear protein of unknown function & +4.1 & +2.6 & +1.8 & +2.4 \\
\hline YDR034W-B & YDR034W-B & Protein of unknown function & +7.2 & +5.0 & +3.6 & +4.5 \\
\hline YML125C & PGA3 & Putative cytochrome b5 reductase & +1.6 & +2.7 & +3.0 & +2.4 \\
\hline YBL107C & YBL107C & Putative protein of unknown function & +2.4 & +2.6 & +2.1 & +2.9 \\
\hline YBR255C-A & YBR255C-A & Putative protein of unknown function & +4.0 & +2.0 & +1.8 & +2.1 \\
\hline YER137C & YER137C & Putative protein of unknown function & +2.9 & +2.4 & +2.5 & +3.6 \\
\hline YGR111W & YGR111W & Putative protein of unknown function & +2.1 & +2.2 & +4.3 & +7.1 \\
\hline YHR138C & YHR138C & Putative protein of unknown function & +4.2 & +2.8 & +2.4 & +2.8 \\
\hline YKR011C & YKR011C & Putative protein of unknown function & +4.6 & +2.3 & +1.9 & +1.3 \\
\hline YNL155W & YNL155W & Putative protein of unknown function & +3.7 & +2.4 & +2.2 & +1.9 \\
\hline YOR059C & YOR059C & ORF, Uncharacterized & +2.1 & +2.6 & +2.2 & +2.2 \\
\hline
\end{tabular}

ARG4, ARG5,6, ARG7, and ARG8 involved in arginine biosynthesis repressed by HMF were regulated by the transcription factor genes $A R G 80$ and $A R G 81$, as well as GCN4 (Additional file $3 \mathrm{~A}$ and $3 \mathrm{~B}$ ). These transcription factor genes were reported to regulate arginine metabolism $[59,60]$. All of these genes were found to be downregulated under the HMF stress in this study. In addition to regulation of arginine biosynthesis, GCN4 regulates expression of many other genes related to amino acid biosynthesis (Additional file 3B), identified by Natarajan et al [60]. Numerous genes involved in biosynthesis of histidine, leucine, and lysine were repressed under the control of GCN4. Among the genes repressed by HMF, a large number of genes are involved in ribosome biogenesis and protein translation processes, which were predicted to be regulated by transcription factor genes RAP1 and FHL1 (Additional file 3C). At the same time, RAP1 and FHL1 also showed repressed expression response.

\section{Deletion mutation response to HMF}

All selective single gene deletion mutations displayed normal growth similar to their parental strain in the absence of HMF treatment on SC medium (Figure 7A). In the presence of HMF, the parental strain BY4742 showed a delayed growth response on SC medium. In contrast, all tested deletion mutations for genes $Y A P 1$, RPN4, PDR1, PDR3, YAP4, YAP5, YAP6, ADH6, ADH7, 
Table 2 Gene Ontology (GO) categories and terms for significantly induced genes by HMF during the lag phase in Saccharomyces cerevisiae

\begin{tabular}{|c|c|c|}
\hline GO ID & GO term & Gene(s) \\
\hline \multicolumn{3}{|c|}{ Cellular component } \\
\hline GO:0005737 & Cytoplasm & $\begin{array}{l}\text { SHP1*, ATG8, YBL107C, HSP26, NPL4, CHA1, GPM2, SNQ2, RPN9, SLF1, SSA4, OTU1, RPN12, } \\
\text { PYC1, ARI1, YGR111W, ECM29, PUT2, PRE3, MET3, MET14, TPO1, ALT1, PUT1, YAP1, PGA3, } \\
\text { ERO1, YNL155W, PRE6, GRE2, SGT2, RSB1, YOR059C, PDR5, TPO4, PRE10, ALD4, CAR1 }\end{array}$ \\
\hline GO:0005634 & Nucleus & $\begin{array}{l}\text { SHP1, YBL100W-A, HSP26, RAD16, RPT2, RPN4, YDR210W-B, YDR316W-B, YDR365W-B, PRE1, } \\
\text { SSA4, MAG1, OTU1, ARI1, YGR111W, ECM29, YKR011C, YAP1, YNL155W, GRE2, YOR052C, RPT4 }\end{array}$ \\
\hline GO:0016020 & Membrane & ATG8, NPL4, SNQ2, PDR15, DDI1, YOR1, TPO1, PGA3, RSB1, PDR5, TPO4, MCH5, PDR12, PRM4 \\
\hline GO:0005575 & Cellular component unknown & IMD1, YBR062C, YBR255C-A, YDR034W-B, YER137C, YGR035C, YHR138C, YLLO56C, ICT1, OYE3 \\
\hline GO:0005886 & Plasma membrane & SNQ2, DDI1, YOR1, TPO1, PGA3, RSB1, PDR5, TPO4, MCH5, PDR12 \\
\hline GO:0005739 & Mitochondrion & CHA1, SNQ2, PUT2, MET3, ALT1, PUT1, PRE6, PDR5, ALD4 \\
\hline GO:0005783 & Endoplasmic reticulum & NPL4, PGA3, ERO1, RSB1 \\
\hline GO:0005773 & Vacuole & ATG8, TPO1, TPO4 \\
\hline GO:0005624 & Membrane fraction & SNQ2, YOR1 \\
\hline GO:0005933 & Cellular bud & TPO1 \\
\hline GO:0005618 & Cell wall & TIR4 \\
\hline GO:0012505 & Endomembrane system & NPL4 \\
\hline GO:0030427 & Cite of polarized growth & CAR1 \\
\hline Other & Other & PRE7, ADH7, RPT3, PUP3 \\
\hline \multicolumn{3}{|c|}{ Biological process } \\
\hline GO:0008150 & Biological process unknown & $\begin{array}{l}\text { IMD1, YBL107C, YBR062C, YBR255C-A, GPM2, YDR034W-B, YER137C, ARI1, YGR035C, YKR011C, } \\
\text { YLL056C, YNL155W, TIR4, YOR052C, YOR059C, PRM4, OYE3 }\end{array}$ \\
\hline GO:0044257 & Cellular protein catabolic process & $\begin{array}{l}\text { PRE7, SHP1, RAD16, NPL4, RPT2, RPT3, RPN9, PRE1, PUP3, DDI1, RPN12, PRE3, PRE6, RPT4, } \\
\text { PRE10 }\end{array}$ \\
\hline GO:0006810 & Transport & ATG8, PDR15, SSA4, DDI1, YOR1, TPO1, PGA3, RSB1, PDR5, TPO4, MCH5, PDR12 \\
\hline GO:0006950 & Response to stress & ATG8, HSP26, RAD16, RPN4, SNQ2, PRE1, SSA4, MAG1, PRE3, YAP1, SGT2 \\
\hline GO:0042221 & Response to chemical stimulus & RPN4, SNQ2, PDR15, YOR1, MET14, YAP1, PDR5 \\
\hline GO:0006519 & $\begin{array}{l}\text { Cellular amino acid and derivative } \\
\text { metabolic process }\end{array}$ & CHA1, PUT2, MET3, MET14, ALT1, PUT1, CAR1 \\
\hline GO:0032196 & Transposition & YBL100W-A, YDR210W-B, YDR316W-B, YDR365W-B \\
\hline GO:0006457 & Protein folding & HSP26, SSA4, ERO1 \\
\hline GO:0006350 & Transcription & RPN4, OTU1, YAP1 \\
\hline GO:0006464 & Protein modification process & RAD16, OTU1, ERO1 \\
\hline GO:0030435 & $\begin{array}{l}\text { Sporulation resulting in formation } \\
\text { of a cellular spore }\end{array}$ & SHP1, PRE1, PRE3 \\
\hline GO:0006259 & DNA metabolic process & RAD16, RPN4, MAG1 \\
\hline GO:0016044 & Membrane organization & ATG8, YHR138C, RSB1 \\
\hline GO:0007033 & Vacuole organization & ATG8, YHR138C \\
\hline GO:0044262 & $\begin{array}{l}\text { Cellular carbohydrate metabolic } \\
\text { process }\end{array}$ & SHP1, PYC1 \\
\hline GO:0044255 & Cellular lipid metabolic process & ICT1, GRE2 \\
\hline GO:0006766 & Vitamin metabolic process & PYC1, ALD4 \\
\hline GO:0046483 & Heterocycle metabolic process & PUT2, PUT1 \\
\hline GO:0051186 & Cofactor metabolic process & PYC1, ALD4 \\
\hline GO:0016192 & Vesicle-mediated transport & ATG8, DDI1 \\
\hline GO:0051276 & Chromosome organization & RAD16 \\
\hline GO:0016070 & RNA metabolic process & YAP1 \\
\hline GO:0006412 & Translation & SLF1 \\
\hline GO:0006091 & $\begin{array}{l}\text { Generation of precursor } \\
\text { metabolites and energy }\end{array}$ & SHP1 \\
\hline GO:0070271 & Protein complex biogenesis & RPN9 \\
\hline GO:0007049 & Cell cycle & RPN4 \\
\hline GO:0019725 & Cellular homeostasis & SLF1 \\
\hline Other & Other & $A D H 7$, YGR111W, ECM29 \\
\hline
\end{tabular}


Table 2 Gene Ontology (GO) categories and terms for significantly induced genes by HMF during the lag phase in Saccharomyces cerevisiae (Continued)

\begin{tabular}{|c|c|c|}
\hline \multicolumn{3}{|c|}{ Molecular function } \\
\hline GO:0016787 & Hydrolase activity & $\begin{array}{l}\text { PRE7, RAD16, RPT2, SNQ2, YDR210W-B, YDR316W-B, YDR365W-B, RPT3, PDR15, PRE1, PUP3, } \\
\text { SSA4, MAG1, OTU1, RPN12, YOR1, PRE3, PRE6, RSB1, PDR5, RPT4, PRE10, PDR12, CAR1 }\end{array}$ \\
\hline GO:0003674 & Molecular function unknown & $\begin{array}{l}\text { IMD1, ATG8, YBL107C, YBR062C, NPL4, YBR255C-A, GPM2, YDRO34W-B, YER137C, YGR035C, } \\
\text { YGR111W, YKR011C, YLLO56C, PGA3, YNL155W, SGT2, TIR4, YOR052C, YOR059C, PRM4 }\end{array}$ \\
\hline GO:0008233 & Peptidase activity & $\begin{array}{l}\text { PRE7, RPT2, YDR210W-B, YDR316W-B, YDR365W-B, RPT3, PRE1, PUP3, OTU1, RPN12, PRE3, } \\
\text { PRE6, RPT4, PRE10 }\end{array}$ \\
\hline GO:0005215 & Transporter activity & SNQ2, PDR15, YOR1, TPO1, RSB1, PDR5, TPO4, MCH5, PDR12 \\
\hline GO:0016491 & Oxidoreductase activity & ADH7, ARI1, PUT2, PUT1, ERO1, GRE2, ALD4, OYE3 \\
\hline GO:0005515 & Protein binding & YBL100W-A, HSP26, YDR210W-B, YDR316W-B, YDR365W-B, SSA4, DDI1, ECM29 \\
\hline GO:0016740 & Transferase activity & YDR210W-B, YDR316W-B, YDR365W-B, MET3, MET14, ALT1, ICT1 \\
\hline GO:0003723 & RNA binding & YBL100W-A, YDR210W-B, YDR316W-B, YDR365W-B, SLF1 \\
\hline GO:0016779 & Nucleotidyltransferase activity & YDR210W-B, YDR316W-B, YDR365W-B, MET3 \\
\hline GO:0003677 & DNA binding & RAD16, RPN4, YAP1 \\
\hline GO:0016874 & Ligase activity & RAD16, PYC1 \\
\hline GO:0030528 & Transcription regulator activity & RPN4, YAP1 \\
\hline GO:0030234 & Enzyme regulator activity & SHP1, YHR138C \\
\hline GO:0016829 & Lyase activity & CHA1 \\
\hline GO:0005198 & Structural molecule activity & RPN9 \\
\hline GO:0016853 & Isomerase activity & GPM2 \\
\hline
\end{tabular}

* Genes in bold indicate their encoding proteins or enzymes are involved in more than one function

ALD4, SNQ2, ICT1, SHP1, OTU1, MET3, MET14, CHA1, ALT1, SSA4, OYE3, NPL4, MAG1, GRE2, GRE3, $A R I 1, Y B R 062 C$, and $Y E R 137 C$, displayed varied lengths of lag phase (Figure 7B). These represent growth defects at different levels in the absence of the individual genes. Among which, the most profound effect was observed by $\Delta r p n 4$ and $\triangle y a p 1$ for transcription factor genes RPN4 and YAP1 as mentioned above. Metabolic conversion profiles were highly consistent with the growth response. As assayed by HPLC, no glucose consumption was observed for all tested strains during the lag phase (data not shown).

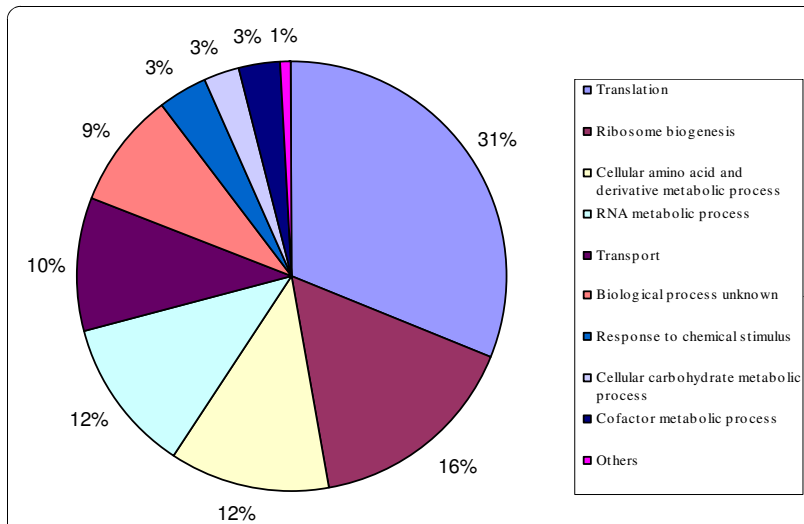

Figure 3 Functional categories of repressed gene expression. Distribution of functional categories of repressed gene expressions by HMF treatment.

\section{Discussion}

Yeast adaptation to lignocellulose derived inhibitor stress is manifest at genome level and likely during the lag phase [23]. Variation in the length of the lag phase has been widely used to measure the tolerance of strains to a specific inhibitor(s). Using DNA 70-mer long oligo microarray and qRT-PCR assays, we investigated comparative transcriptome profilings of $S$. cerevisiae during the lag phase under HMF challenge in a time-course study. Our comprehensive analyses uncovered important

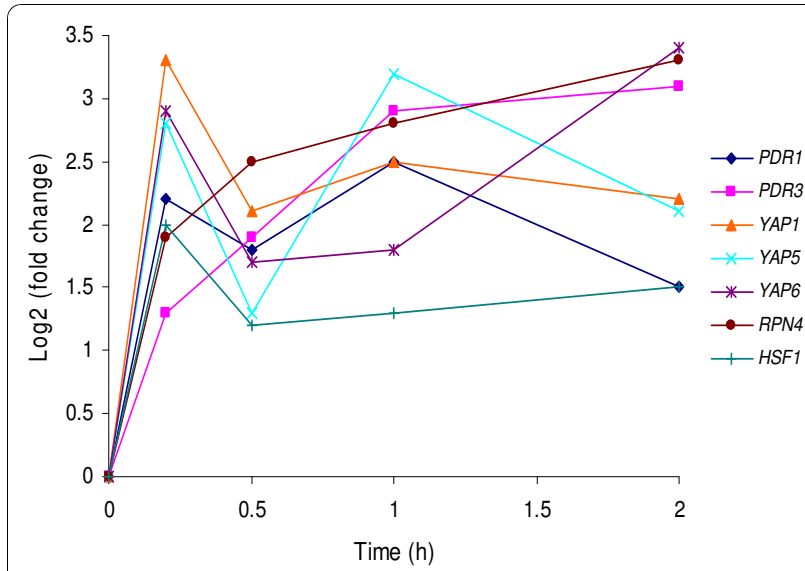

Figure 4 Expression response of important transcription factor genes. Expression patterns of seven selective genes encoding important transcription factors for positively regulating gene expression response to HMF stress. 


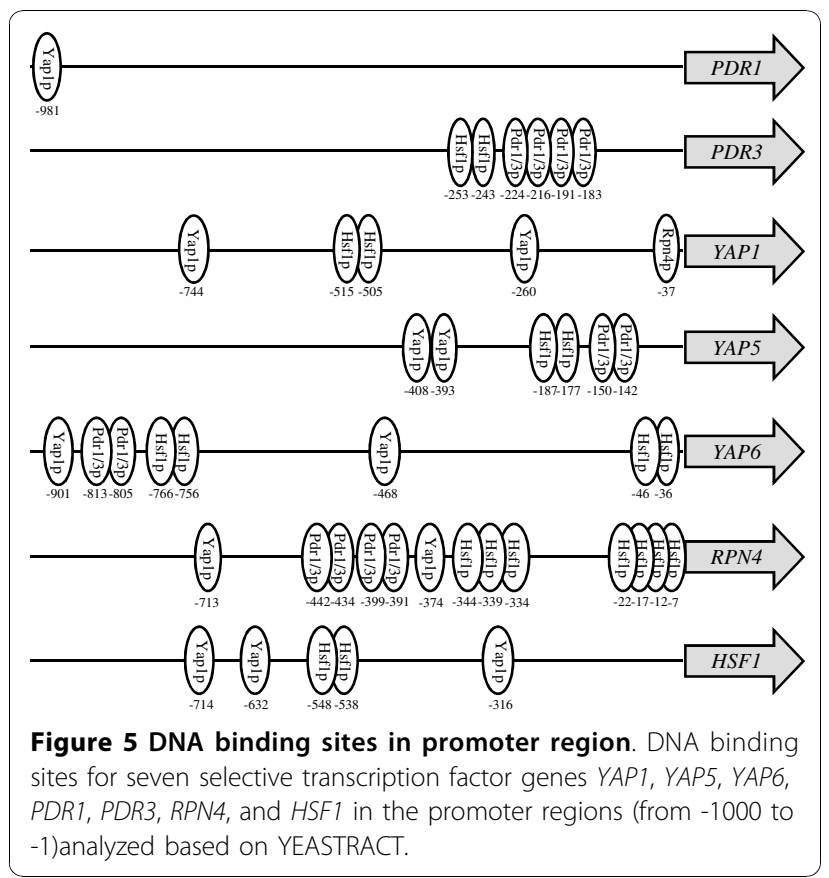

transcription factor genes, including YAP1, YAP5, YAP6, $P D R 1, P D R 3, R P N 4$, and $H S F 1$, as key regulators for the yeast adaptation, as well as their co-regulation and complicated regulatory networks with numerous multiple function genes. We identified more than 300 genes showing statistically significant differential expression responses that potentially affect yeast adaptation to the inhibitor challenge. Among which, more than 70 genes were consistently induced and more than 200 genes were repressed at varied stages during the lag phase. This is the first report of systematic analysis on genomic expression to inhibitor stress during the lag phase in the context of yeast adaptation. Knowledge obtained from this study provides insight into global adaptive responses of the yeast to inhibitor stress and aids the dissection of tolerance mechanisms of the yeast.

Our studies uncovered at least three significant elements for yeast adaptation to inhibitor stress and mechanisms of tolerance. The first component involves the functional enzymes and related regulatory networks directly involved in biotransformation and inhibitor

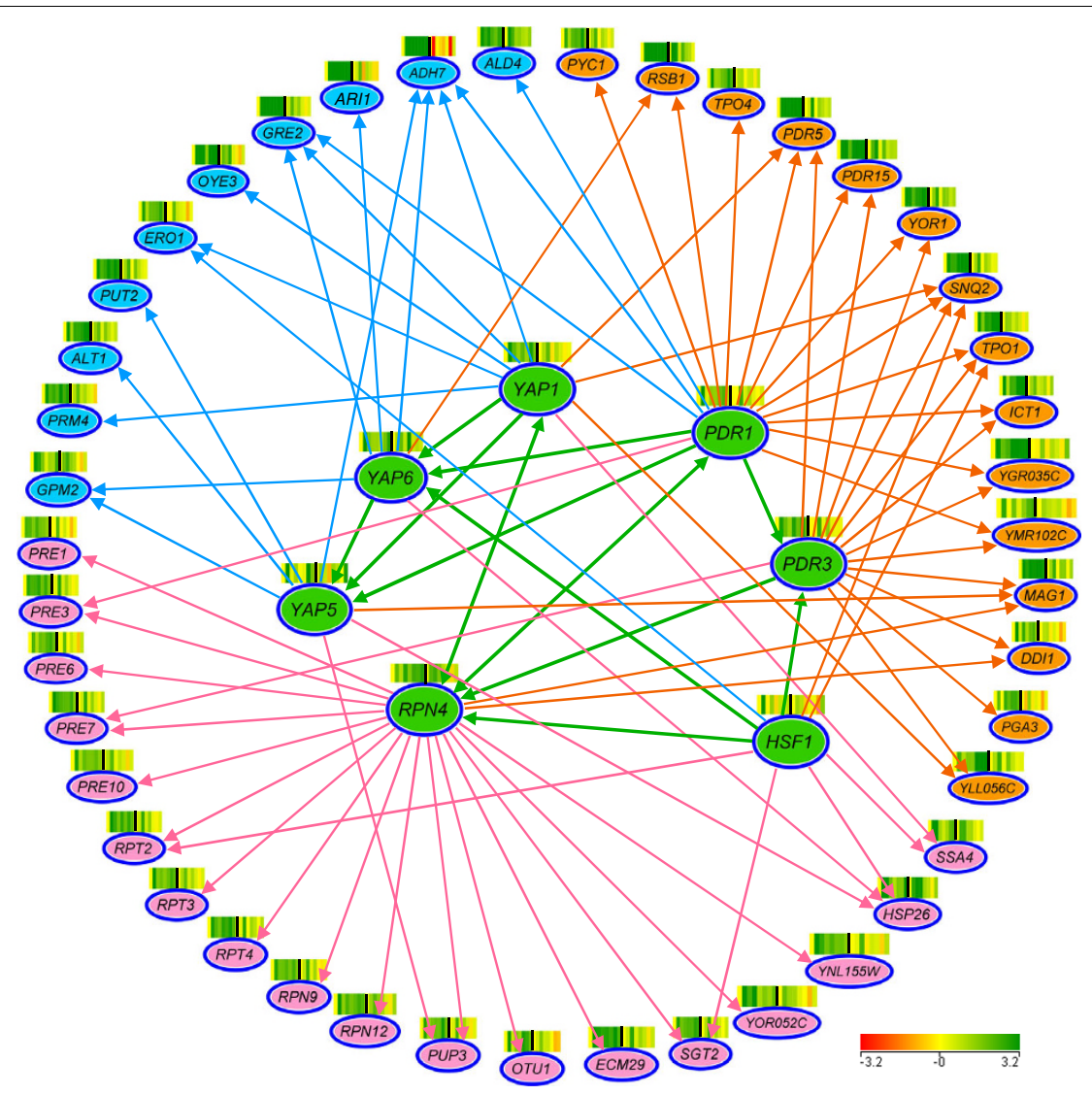

Figure 6 Significant positive gene regulatory networks. Regulatory interaction networks between transcription factors (filled green and green arrows) and induced genes for functional reduction enzymes (filled blue and blue arrows), PDR gene family (filled orange and orange arrows), and proteasome function (filled pink and pink arrows). Scales of the expression are indicated by an integrated color bar at the right bottom corner. 

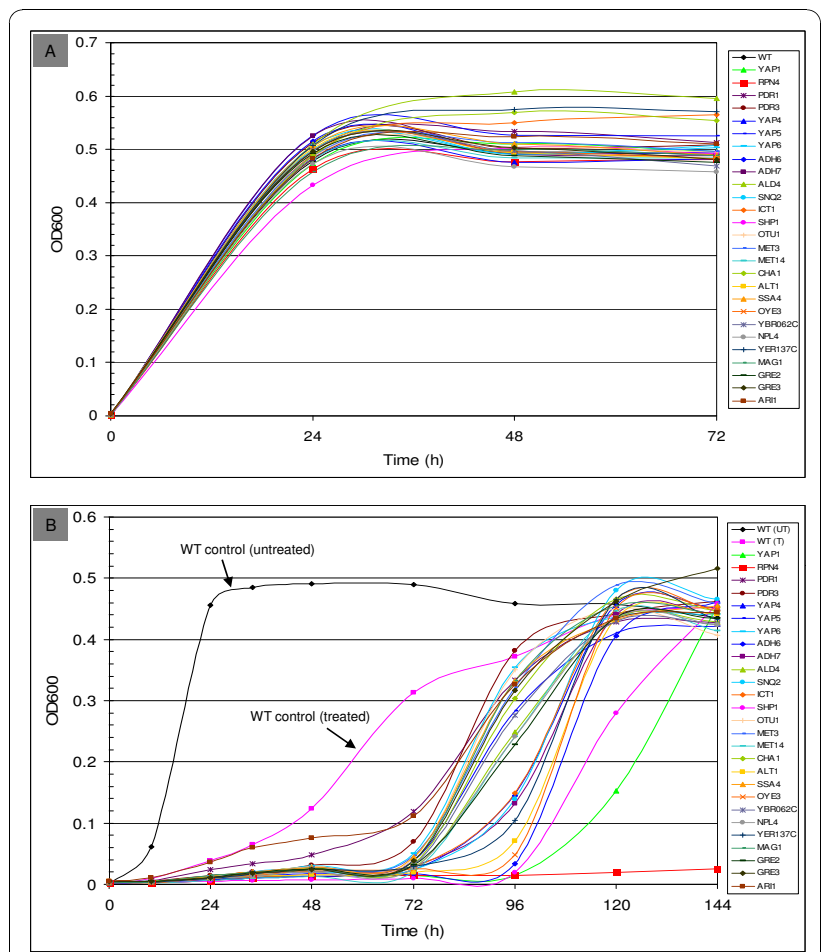

Figure 7 Deletion mutants growth response to HMF. Cell growth of deletion mutations and the parental wild type BY4742 (WT) on SC medium without HMF (A) and in the presence of 15 $\mathrm{mM}$ HMF (B) as measured by $\mathrm{OD}_{600}$ over time. Legend for each mutation is provided by a color code.

detoxification. At a sublethal dose, yeasts are able to convert HMF into less toxic compound FDM. The in situ detoxification of HMF has been identified as a primary mechanism of the tolerance for yeast strains [5]. This is mainly accomplished via the activity of functional reductase and numerous enzymes possessing $\mathrm{NAD}(\mathrm{P}) \mathrm{H}$-dependent aldehyde reduction activities, such as enzyme encoding genes ADH6, ADH7, ALD4, ARI1, ARI2, ARI3, OYE3, GRE2, and GRE3 [[26,27,61-64], Liu, unpublished data]. In this study, we found $A D H 7, A R I 1$, GRE2, and $A L D 4$ were immediately induced by the addition of HMF, especially for $A D H 7$ which displayed a greater than 30-fold increase in transcription abundance 10 min after the HMF addition and 80-fold increase at $1 \mathrm{~h}$. The expression of $A D H 7$ was regulated by Yap1p, Yap5p, Yap6p, and Pdr1p (Figure 6). Multiple layers of up-regulated expressions of $A D H 7$ provide strong support for its extremely high levels of induction. On the other hand, it indicated the significant roles of $A D H 7$ in adaptation to the aldehyde inhibitor challenge and tolerance to the inhibitor. Most reductase genes are regulated by Yap1p and related regulons Yap5p and Yap6p. A few enzyme encoding genes for example, $A L D 4$ and GRE2 were co-regulated by Pdr1p. It should be pointed out that multiple functions of a gene are common and the co-regulation can be a reflection of the multifunctions.

As mentioned above, conversion of aldehyde inhibitors including $\mathrm{HMF}$, consumes cofactor $\mathrm{NAD}(\mathrm{P}) \mathrm{H}$ and redox imbalance often causes damage in cell metabolism. We have previously demonstrated that tolerant yeast cells utilize reprogrammed pathways to detoxify aldehyde inhibitors and favored pentose phosphate pathway in regeneration of cofactors keeping a well maintained redox balance $[29,65]$. In this study, we found the yeast, during the lag phase, appeared to facilitate a short path to the TCA cycle from which energy and NAD $(\mathrm{P}) \mathrm{H}$ regeneration can be achieved. This involved genes in the amino acids metabolism pathways closely related to the TCA cycle, both induced genes such as CHA1, ALT1, PUT1, PUT2, and CAR1, and repressed genes such as ARG1, ARG3, ARG4, ARG5,6, ARG7, ARG8, LYS4, $L Y S 14$, and LYS20 (Figure 9). The accelerated catabolism of proline, serine, and alanine, together with the reduced biosynthesis of arginine likely provided a shortcut for ATP regeneration via the TCA cycle. Thus, efficient energy metabolism can be maintained under the HMF stress. These findings suggest the altered pathway is an adaptation response that allows sufficient production of intermediate substrates for energy and NAD $(\mathrm{P}) \mathrm{H}$ regeneration through the TCA cycle under the HMF challenge. Many of these genes, for example, PUT2 and $A L T 1$ are regulated by YAP1 and its related YAP gene family. Yap1p has been reported as involved in the regulation of numerous other anti-oxidant genes [66-68]. It also plays a significant role for DNA damage repairing [69]. The preferred Yap1p binding site is TTACTAA [39]. We found many reductase genes that contribute to the biotransformation of the inhibitors have the Yap1p binding site in their promoter regions and are likely regulons of Yap1p.

The second element we found to be significant for yeast survival and adaptation under the HMF challenge is the PDR gene family-centered functions that are regulated by $\mathrm{Pdr} 1 / 3 \mathrm{p}$ and as well as other regulator genes such as YAP1 and HSF1. Some PDR genes function as transporters of ATP-binding cassette proteins and encode plasma membrane proteins. These genes mediate membrane translocation of ions and a wide range of substrates and often exhibit multiple functions in response to a large variety of unrelated chemical stresses [42-45]. In this study, we found at least 15 members of the PDR gene family were significantly induced by HMF. The membrane and transporter activity related functions are mainly documented for these genes. For example, TPO1 and TPO4 encode proteins to function as drug/toxin transport and multidrug efflux pumps [70,71], RSB1 for transport ATPase, and PDR15 for 
ABC transporters, specifically. Other genes encode proteins that have multiple functions covering all of these categories, such as SNQ2, YOR1, PDR5, and PDR12 (Table 3 ). In addition, proteins encoded by these genes also perform functions of ATP binding and other cytoplasmic and molecular functions. Confirmed by deletion mutation assays of cell growth and qRT-PCR, we reasonably speculate that $\mathrm{ABC}$ transporters play a key role to export excessive HMF and endogenous toxic metabolites from intracellular environment brought about by HMF damage. As mentioned above, the shortcut of the TCA cycle could provide energy for the pumping of HMF and toxic metabolites by ABC transporters.

In this group, we observed induced transcriptional response of $R S B 1$ and $I C T 1$. These two genes are involved in phospholipid synthesis and transportation for membrane structure and functions, and are responsible for tolerance to organic solvents in $S$. cerevisiae $[72,73]$. It is possible that the induction of these PDR genes prevents the fast influx of HMF into cytoplasm and important organelles by membrane remodeling, thus, increasing the cell's tolerance to HMF. MAG1 encodes a 3-methyladenine (3MeA) DNA glycosylase [74], which acts in the first step of a multistage base excision repair pathway for the removal of lethal lesions such as $3 \mathrm{MeA}$ and protects yeast cells from killing by DNA-alkylating agents [75]. DDI1, located immediately upstream of MAG1 and transcribed in an opposite direction, encodes an ubiquitin-related protein and is involved in a DNA-damage cell-cycle checkpoint [76].
Another DNA damage related gene $R A D 16$ was also induced by HMF [77]. The induction of MAG1, DDI1, and $R A D 16$ in this study are consistent with the potential DNA damage by HMF and yeast defense response to the HMF challenge. Regulatory interactions of PDR gene family are complex and many genes appeared to be regulated by multiple transcription factor genes involving PDR1, PDR3, YAP1, and HSF1. Regulatory roles of $P D R 1$ and $P D R 3$ to HMF challenge were suggested by computational modeling $[78,79]$. Our deletion mutation assays using qRT-PCR suggest PDR 1 may have direct interactive effects with more induced genes than PDR3, but PGA3 appeared to be regulated by PDR3. However, detailed interactions of the multiple functions of most PDR genes remain largely unknown, which can be related to the multiple regulated interactions by YAP1, PDR1, PDR3, and HSF1 as outlined by this study.

The third component of the yeast adaptation response to HMF involves degradation of damaged proteins and protein modifications mainly regulated by transcription factor genes RPN4 and HSF1. Chemical stress causes damage to protein conformation leading to protein unfolding and aggregation [80]. Small heat shock proteins, acting as chaperones, assist in folding or refolding nascent or denatured proteins and enzymes to maintain a functional conformation [81]. In this study, we found HSP26 and SSA4 encoding chaperones were significantly induced to counteract HMF stress damage to proteins. The deletion mutation of SSA4 displayed a significant longer lag phase under the HMF challenge, indicating

Table 3 Protein functional categories for significantly induced genes by HMF during the lag phase in Saccharomyces cerevisiae

\begin{tabular}{|c|c|c|c|}
\hline MIPS ID & Functionary category & p-value & Entries \\
\hline \multicolumn{4}{|l|}{01 Metabolism } \\
\hline 01.01.03.03.02 & Degradation of proline & $7.82 \mathrm{E}-04$ & PUT2, PUT1* \\
\hline 01.01.03.05.02 & $\begin{array}{l}\text { Degradation of } \\
\text { arginine }\end{array}$ & $3.94 \mathrm{E}-04$ & PUT1, CAR1 \\
\hline 01.02.03.01 & Sulfate assimilation & $3.54 \mathrm{E}-03$ & MET3, MET14 \\
\hline \multicolumn{4}{|c|}{14 Protein fate (folding, modification, destination) } \\
\hline 14.07.11 & $\begin{array}{l}\text { Protein processing } \\
\text { (proteolytic) }\end{array}$ & 4.05E-09 & PRE7, ATG8, RPT2, RPT3, PRE1, PUP3, RPN12, PRE3, PRE6, RPT4, PRE10 \\
\hline 14.13 & $\begin{array}{l}\text { Protein/peptide } \\
\text { degradation }\end{array}$ & 3.97E-11 & $\begin{array}{l}\text { PRE7, SHP1, ATG8, NPL4, RPT2, RPN4, RPT3, RPN9, PRE1, PUP3, DDI1, OTU1, RPN12, ECM29, } \\
\text { YHR138C, PRE3, PRE6, RPT4, PRE10 }\end{array}$ \\
\hline \multicolumn{4}{|c|}{16 Protein with binding function or cofactor requirement (structural or catalytic) } \\
\hline 16.19 .03 & ATP binding & $1.52 \mathrm{E}-03$ & RPT2, SNQ2, RPT3, PDR15, YOR1, PDR5, RPT4, PDR12 \\
\hline \multicolumn{4}{|c|}{20 Cellular transport, transport facilities and transport routes } \\
\hline 20.01.27 & Drug/toxin transport & 4.70E-06 & SNQ2, YOR1, TPO1, PDR5, TPO4, PDR12 \\
\hline 20.03.22 & Transport ATPases & $3.68 \mathrm{E}-04$ & SNQ2, YOR1, RSB1, PDR5, PDR12 \\
\hline 20.03 .25 & $A B C$ transporters & $1.44 \mathrm{E}-05$ & SNQ2, PDR15, YOR1, PDR5, PDR12 \\
\hline \multicolumn{4}{|c|}{32 Cell rescue, defense and virulence } \\
\hline 32.05 .01 .03 & $\begin{array}{l}\text { Chemical agent } \\
\text { resistance }\end{array}$ & $1.73 \mathrm{E}-05$ & SNQ2, MAG1, YOR1, YAP1, PDR5 \\
\hline
\end{tabular}

\footnotetext{
* Proteins in bold indicate functions involved in more than one category
} 

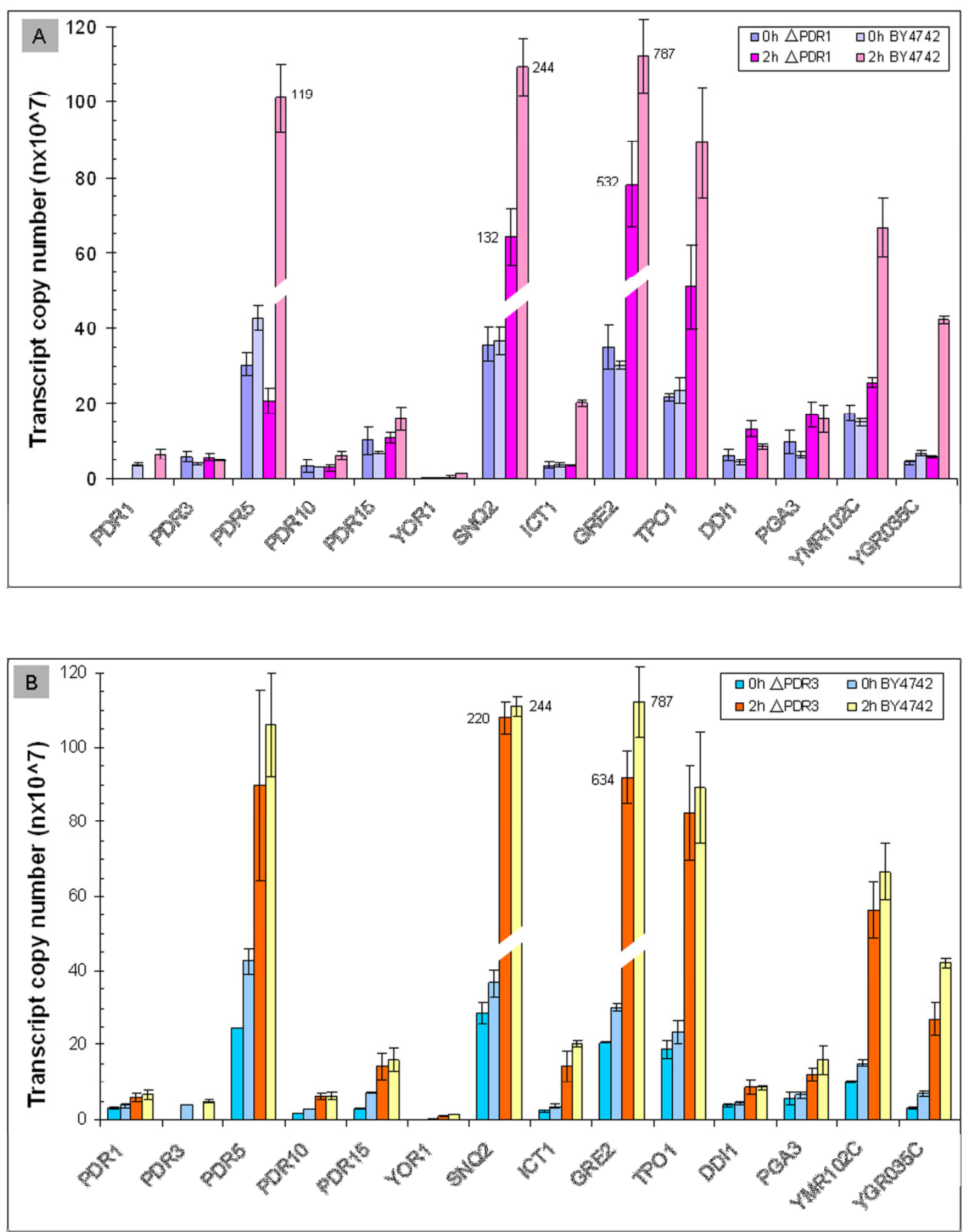

Figure 8 The qRT-PCR for PDR gene family. Expression abundance and gene interactions affected by deletion mutation $\triangle p d r 1$ (A) and $4 p d r 3$ (B) for selected PDR genes in response to HMF challenge compared with their parental wild type strain BY4742. Mean values are presented with error bars of standard deviations. Legend of value specificity is provided.

its important role in adaptation and tolerance to HMF. While the presence of chaperones provides positive contribution to protein protection, severe or prolonged stress condition can result in irreversible protein damage. Misfolded or damaged proteins, especially aggregated proteins are highly toxic to cells [80]. Degradation of misfolded and damaged proteins by the ubiquitin-mediated proteasome pathway plays an important 


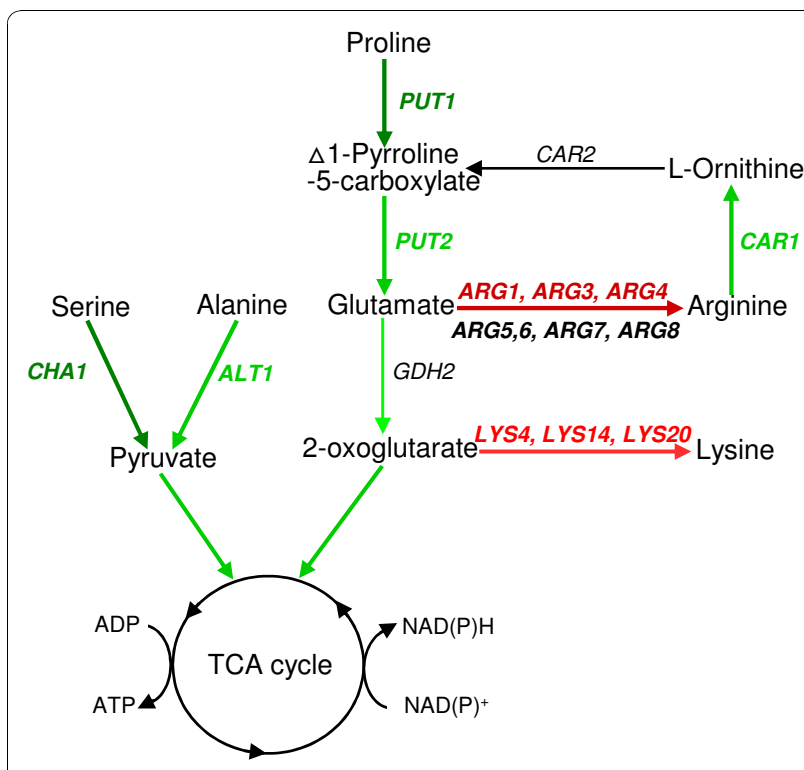

Figure 9 Pathways affected toward TCA cycle. Pathways involved in metabolisms of serine, alanine, proline, lysine, and arginine toward TCA cycle for ATP and $\mathrm{NAD}(\mathrm{P}) \mathrm{H}$ regeneration are significantly affected by HMF challenge. Bolded letters and arrowed lines indicate the levels of expressions and pathways are statistically significant. Enhanced expressions and pathways are in green and repressed in red. Black letters and arrowed lines indicate normal expressions and pathways.

role in maintaining normal cell function and viability $[80,82,83]$. Denatured proteins are targeted via the covalent attachment of ubiquitin to a lysine side chain, and polyubiquitinated proteins are finally delivered to proteasome to be degraded. We observed that at least 14 ubiquitin-related and proteasome genes were induced by HMF (Figure 4B, Table 1), indicating their important functions in adaptation to the HMF stress. Strains with deletion mutations in these genes were sensitive to HMF with an extended lag phase, for example, genes OTU1 and SHP1. It was suggested that the degradation of proteins by the ubiquitin-mediated proteasome pathway has regulatory roles on cell cycle, metabolic adaptations, gene regulation, development, and differentiation [84].

As indicated by our study, many genes involved in the degradation of damaged protein and protein modifications are regulated by transcription factor gene RPN4. Our deletion mutation assays of RPN4 showed normal growth in the absence of HMF but no growth with the HMF treatment. These results confirmed the vital role of RPN4 involvement in adaptation to survival and coping with the HMF challenge. Since HSF1 is an essential gene, no deletion mutant test was performed.

\section{Conclusions}

Among 365 genes identified as differentially expressed under HMF challenges, both induced and repressed genes of multiple functional categories are associated with the yeast adaptation to the inhibitor HMF during the lag phase. Transcription factor genes YAP1, PDR1, $P D R 3, R P N 4$, and $H S F 1$ were identified as key regulatory genes for yeast global adaptation. Functional enzyme coding genes, for example ARI1, ADH6, $A D H 7$, and $O Y E 3$, as well as gene interactions involved in the biotransformation and regulated by $Y A P 1$, are directly involved in the conversion of HMF into the less toxic compound FDM. PDR genes encode plasma membrane proteins and function as transporter of ATP-binding cassette proteins. The large number of induced PDR genes observed by our study suggests a hypothesis of the important PDR function of pumping HMF and endogenous toxic metabolites to maintain cell viability. Important PDR gene functions include specific transporter ATPase gene RSB1, toxin transporter genes TPO1 and TPO4, and multiple cellular transport facilitator genes PDR5, PDR12, PDR15, YOR1, and SNQ2. In addition, highly expressed genes involving degradation of damaged proteins and protein modifications regulated by RPN4, HSF1, and other co-regulators appear to be necessary for yeast survival and adaption to the HMF stress. Mutant strain $\Delta r p n 4$ was unable to recover growth in the presence of HMF suggesting a significant regulatory role of RPN4 for many regulons. Complex gene interactions and regulatory networks as well as coregulation events exist in response to the lignocellulose derived inhibitor HMF (Figure 10). Results from this study provide insight into mechanisms of adaptation and tolerance by the yeast Saccharomyces cerevisiae that will directly aid continued engineering efforts for more tolerant yeast development.

\section{Methods}

\section{Strain, medium, and cultivation condition}

S. cerevisiae strain NRRL Y-12632 (Agricultural Research Service Culture Collection, Peoria, IL, USA) was used in this study. The yeast was maintained and cultured on a synthetic complete (SC) medium as previously described [24]. Nonessential haploid S. cerevisiae deletion mutations generated by the Saccharomyces Genome Deletion Project [85] and the parental train BY4742 (MAT $\alpha$ his $3 \Delta 1$ leu2 $\Delta 0$ lys $2 \Delta 0$ ura $3 \Delta 0$ ) were obtained from Open Biosystems (Huntsville, AL). Culture inocula were prepared using freshly grown cells harvested at logarithmic growth phase after incubation with agitation of $250 \mathrm{rpm}$ at $30^{\circ} \mathrm{C}$ for $16 \mathrm{~h}$. Cells were incubated on SC medium in a fleaker fermentation system (aerobic) at $30^{\circ} \mathrm{C}$ with agitation as described previously $[24,28]$. HMF was added into the culture at a final concentration of $30 \mathrm{mM} 6 \mathrm{~h}$ after the inoculation. Cultures grown under the same conditions without the HMF treatment served as a control. Two 


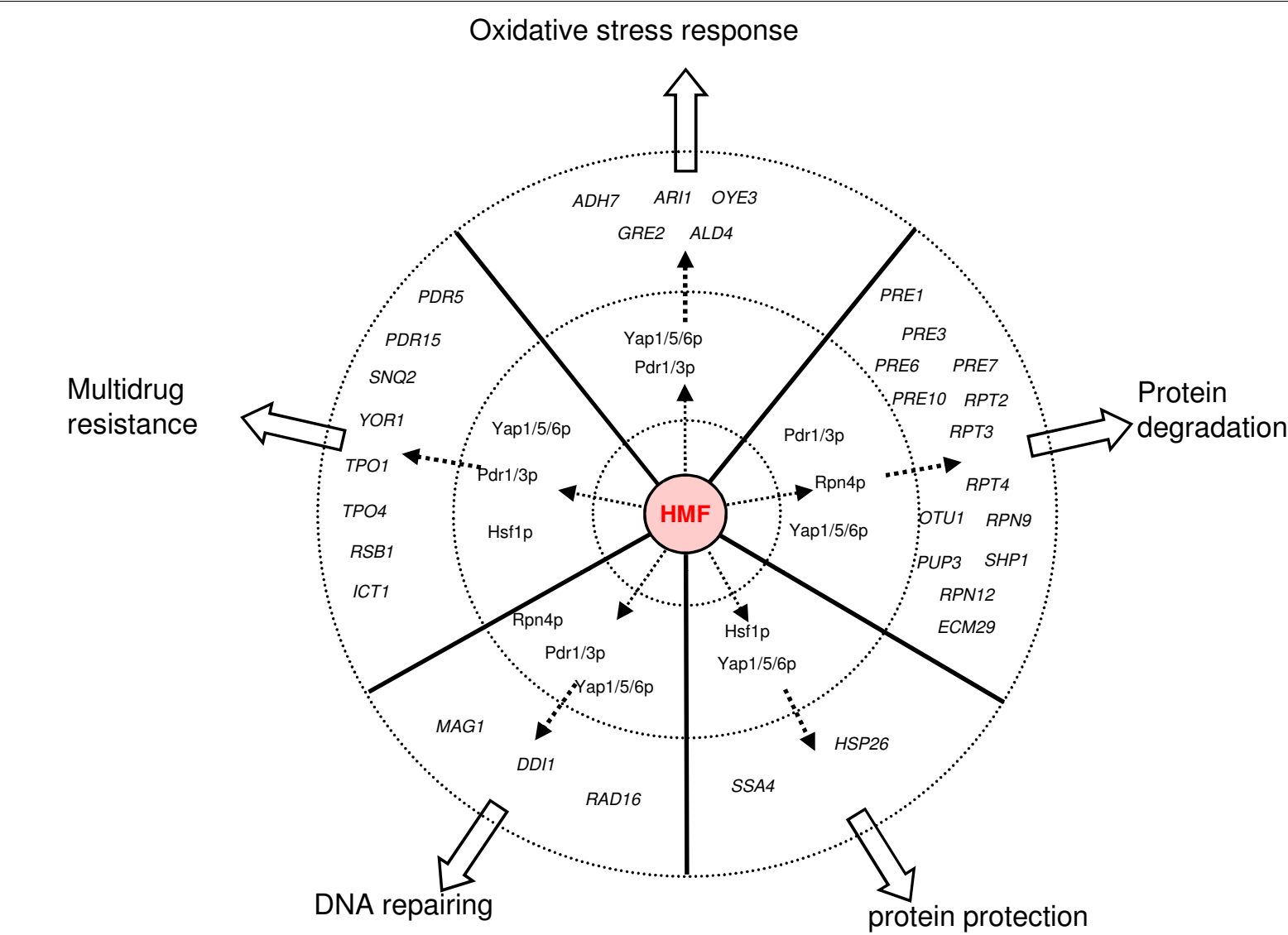

Figure 10 Yeast response to HMF. A schematic diagram of gene regulatory networks involving selective genes and significant regulatory elements in yeast response to HMF stress.

replicated experiments were carried out for each condition.

\section{Cell treatment and sample collection}

Cell growth was monitored by absorbance at $\mathrm{OD}_{600}$ during the fermentation. The time point at the HMF addition after 6 -h pre-culture was designated as 0 time point. At 0, 10, 30, 60, 120 min after the HMF treatment, cell samples were harvested by centrifugation at $3645 \mathrm{~g}$ for $2 \mathrm{~min}$ at room temperature. Cell pellets were immediately frozen on dry ice and then stored at $-80^{\circ} \mathrm{C}$ until use. Culture supernatants were taken periodically from $0 \mathrm{~h}$ to $54 \mathrm{~h}$ for metabolic profiling analysis. Glucose consumption, ethanol conversion, HMF, and FDM were measured using a high performance liquid chromatography (HPLC) system (Water Corp, Milford, MA) composed of a Waters 717 plus autosampler controlled at $10^{\circ} \mathrm{C}$, Waters 590 programmable pump, an Aminex HPX-87 H column (Bio-Rad Laboratories, Hercules, CA) proceeded by a Microguard cartridge, a SpectraPhysics Spectra 100 variable wavelength UV detector $(215 \mathrm{~nm})$, and a Waters 2414 refractive index detector. The column was maintained at $65^{\circ} \mathrm{C}$, and samples were eluted with $1.6 \mathrm{mM} \mathrm{H}_{2} \mathrm{SO}_{4}$ at $0.6 \mathrm{ml} / \mathrm{min}$ isocratic flow. A standard curve was constructed for each detected chemical and metabolic conversion product for HPLC assays as described previously $[26,28]$.

\section{Microarray design and fabrication}

Genome microarray of $S$. cerevisiae was fabricated with a version of 70-mer oligo set representing 6,388 genes. Using OminGrid 300 Gene Machine (Genomic Solutions, Ann Arbot, MI), a mini-array consisting of quality control genes was designed on the top of the target array for data acquisition reference during pre-scanning [86]. Replicated universal RNA controls were embedded in the target array with 32 replications for each control gene and other quality controls of DNA sequence background and slide background were included. The target genome array was printed in duplicate on a slide. Each microarray slide consisted of approximately 13,000 elements including target genes and quality controls.

RNA isolation, probe, labeling, and hybridization

Total RNA was isolated and purified using RNeasy Mini Kit (QIAGEN, Alameda, CA, USA) using a 
protocol as previously described [86]. RNA integrity was verified by gel electrophoresis and NanoDrop Spectrophotometer ND-100 (NanoDrop Technologies, Inc., Wilmington, DE). RNA probe, together with incorporated RNA controls, was labeled using an indirect dUTP Cy3 or Cy5 dye as described previously [86]. Cy5 labeled RNA at 0 time point was designated as a reference and $\mathrm{Cy} 3$ was used to label test samples. An equal amount of at least $30 \mathrm{pmol} \mathrm{Cy} 3$ and $\mathrm{Cy} 5$ labeling reaction was applied for hybridization. Hybridization was performed based on Hegde et al [87] with modifications using HS 4800 Hybridization station (TECAN, Research Triangle Park, NC, USA).

\section{Data acquisition and analysis}

Microarray slides were scanned using a GenePix 4000B scanner (Axon Instruments, Union City, CA, USA) and data acquisition was performed applying universal RNA controls using GenPix Pro V 6.0 software (Molecular Devices, Sunnyvale, CA, USA). A pre-scan control mini-array was used to adjust PMT Gain against $\mathrm{Cy} 3$ and $\mathrm{Cy} 5$ channels and the ratios of signal intensities between $\mathrm{Cy} 3$ and $\mathrm{Cy} 5$ were balanced to 1.0 using the calibration control as described previously [86]. Each spot was individually examined and adjusted or flagged out if necessary. Microarray data was deposited at the Gene Expression Omnibus (GEO) database under Accession "GSE22939". Median of foreground signal intensity subtracted by background for each dye channel was used for analysis. Raw data for each slide were normalized based on spike-in control gene $C A B$, and normalized data were analyzed using GeneSpring GX 10.0 (Agilent Technologies, Santa Clara, CA, USA). Briefly, expression values less than 100 in 7 of 16 samples were filtered out from probesets, then a 2-way ANOVA analysis $(p \leq 0.05)$ was performed. Genes showing statistically significant differential expressions with a minimum of 2 -fold changes were selected for Principal Component Analysis and clustering analysis by Hierarchical and Self Organizing Maps. Interaction pathway analyses were modified and incorporated with the most up-to-date information. Gene functions were annotated using the Saccharomyces genome database (SGD) Gene Ontology Term Finder version 0.83 http://www.yeastgenome.org/cgi-bin/GO/goTermFinder.pl[88] and MIPS Functional Catalogue [89] with a significant cut-off value of $\mathrm{p}<0.01$. Transcription factor analysis was performed using the T-Profiler tool [30], and the selected transcription factors were further analyzed using YEASTRACT [31].

\section{Deletion mutation response to HMF}

Twenty-seven single gene deletion mutations from Saccharomyces Genome Deletion Sets were selected for growth response to HMF. These genes include available non essential genes and transcription factor genes $Y A P 1$, RPN4, PDR1, PDR3, YAP4, YAP5, YAP6, ADH6, ADH7, ALD4, SNQ2, ICT1, SHP1, OTU1, MET3, MET14, CHA1, ALT1, SSA4, OYE3, NPL4, MAG1, GRE2, GRE3, $A R I 1, Y B R 062 C$, and YER137C. A parental strain BY4742 (WT) grown with and without HMF treatment served as a control. Each tested strain was grown on a 4 $\mathrm{ml} \mathrm{SC}$ medium in a $15-\mathrm{ml}$ tube at $30^{\circ} \mathrm{C}$ with agitation of $250 \mathrm{rpm}$. Culture inocula were prepared using freshly grown cells harvested at logarithmic growth phase after incubation for $16 \mathrm{~h}$. The initial OD at $600 \mathrm{~nm}$ of the inoculated medium for each deletion strain culture was adjusted to the same level and inoculated onto the SC medium with a final HMF concentration of $15 \mathrm{mM}$. Cell growth was monitored by absorbance at $\mathrm{OD}_{600}$ and culture supernatants were taken periodically for HPLC analysis of glucose consumption, ethanol production, HMF, and FDM conversion as described above.

\section{Quantitative real time RT-PCR assays}

Regulatory interactions among induced expression by transcription factor gene PDR1 and PDR3 were verified applying a single gene deletion mutation $\Delta p d r 1$ and $\Delta p d r 3$ from Saccharomyces Genome Deletion Set using qRT-PCR. Primer design (Additional file 5), PCR profiles, and assay method are as previously described $[29,90]$. HMF and furfural were added into the medium at a final concentration of $15 \mathrm{mM}$ each after $6 \mathrm{~h}$ preculture. The time point at the addition of inhibitors was designated as $0 \mathrm{~h}$. Cell samples were harvested at 0 and $2 \mathrm{~h}$ during the lag phase and RNA extracted as previously described [86].

\section{List of abbreviations}

ABC: ATP-binding cassette; ChIP-chip: chromatin immunoprecipitation associated with microarrays; FDM: furan-2, 5-dimethanol; GEO: Gene Expression Omnibus; GO: gene ontology; HMF: 5-hydroxymethylfurfural; HPLC: high performance liquid chromatography; PACE: proteasomeassociated control elements; PCA: Principal Component Analysis; PDRE: pleiotropic drug response elements; ROS: reactive oxygen species; SC medium: synthetic complete medium; SNP: single nucleotide polymorphism; SGD: Saccharomyces genome database; SOM: Self Organizing Maps; TCA cycle: tricarboxylic acid cycle; TF: transcription factor; YEASTRACT: Yeast Search for Transcriptional Regulators And Consensus Tracking; YRE: Yap1p response elements.

\section{Additional material}

Additional file 1: Differential expression of significantly affected genes of Saccharomyces cerevisiae in response to HMF challenges during the lag phase.

Additional file 2: Gene Ontology (GO) categories and terms for significantly repressed genes by HMF (30 mM) challenge in Saccharomyces cerevisiae NRRL Y-12632.

Additional file 3: Regulatory interaction networks for repressed genes under HMF stress. 
Additional file 4: Protein binding motifs and binding elements for significantly induced genes by HMF challenge during the lag phase in Saccharomyces cerevisiae.

Additional file 5: Primers used for mRNA expression analysis for Saccharomyces cerevisiae by real-time qRT-PCR using SYBR Green I.

\section{Acknowledgements}

Authors are grateful to technical assistance from Amy Cash and Scott Weber and to Michael A. Cotta for critical reading of the manuscript. This work was supported in part by the National Research Initiative award of the USDA National Institute of Food and Agriculture, project 2006-35504-17359. The mention of trade names or commercial products in this article is solely for the purpose of providing specific information and does not imply recommendation or endorsement by the U.S. Department of Agriculture.

\section{Authors' contributions}

ZLL conceived the project, designed and fabricated yeast DNA microarray, and conducted the microarray experiments. MM performed the GRT-PCR and deletion mutation assays. MM and ZLL analyzed data and wrote the manuscript. All authors read and approved the final manuscript.

Received: 30 June 2010 Accepted: 24 November 2010

Published: 24 November 2010

\section{References}

1. Bothast RJ, Saha BC: Ethanol production from agricultural biomass substrate. Adv Appl Microbiol 1997, 44:261-286.

2. Zaldivar J, Nielsen J, Olsson L: Fuel ethanol production from lignocellulose: a challenge for metabolic engineering and process integration. Appl Microbiol Biotechnol 2001, 56:17-34.

3. Outlaw J, Collins K, Duffield J: Agriculture as a producer and consumer of energy CAB International, Wallingford, UK; 2005.

4. Hahn-Hägerdal B, Galbe M, Gorwa-Grauslund MF, Lidén G, Zacchi G: Bioethanol-the fuel of tomorrow from the residues of today. Trends Biotechnol 2006, 24:549-556.

5. Liu ZL, Saha BC, Slininger PJ: Lignocellulose biomass conversion to ethanol by Saccharomyces. In Bioenergy.. 1 edition. Edited by: Wall J, Harwood C, Demain A. Washington, DC: ASM Press; 2008:17-36.

6. Sánchez OJ, Cardona CA: Trends in biotechnological production of fuel ethanol from different feedstocks. Bioresour Technol 2008, 99:5270-5295.

7. Wall JD, Harwood CS, Demain A: Bioenergy ASM Press. Washington, DC, USA; 2008.

8. Vertes A, Qureshi N, Yukawa H, Blaschek H: Biomass to biofuels Wiley, West Sussex; 2010.

9. Larsson S, Palmqvist E, Hahn-Hägerdal B, Tengborg C, Stenberg K, Zacchi G, Nilvebrant NO: The generation of inhibitors during dilute acid hydrolysis of softwood. Enzyme Microb Technol 1999, 24:151-159.

10. Luo C, Brink DL, Blanch HW: Identification of potential fermentation inhibitors in conversion of hybrid poplar hydrolyzate to ethanol. Biomass Bioenergy 2002, 22:125-138.

11. Klinke $H B$, Thomsen $A B$, Ahring $B K$ : Inhibition of ethanol-producing yeast and bacteria by degradation products produced during pretreatment of biomass. Appl Microbiol Biotechnol 2004, 66:10-26.

12. Chung IS, Lee YY: Ethanol fermentation of crude acid hydrolyzate of cellulose using high-level yeast inocula. Biotechnol Bioeng 1985, 27:308-315.

13. Taherzadeh MJ, Gustafsson L, Niklasson C, Liden G: Conversion of furfural in aerobic and anaerobic batch fermentation of glucose by Saccharomyces cerevisiae. J Biosci Bioeng 1999, 87:169-174.

14. Liu ZL, Blaschek HP: Lignocellulosic biomass conversion to ethanol by Saccharomyces. In Biomass to biofuels.. 1 edition. Edited by: Vertes A, Qureshi N, Yukawa H, Blaschek H. West Sussex: Wiley; 2010:17-36.

15. Antal MJ, Leesomboon T, Mok WS, Richards GN: Mechanism of formation of 2-furaldehyde from D-xylose. Carbohydr Res 1991, 217:71-85.

16. Lewkowski J: Synthesis, chemistry, and applications of 5hydroxymethylfurfural and its derivatives. Arkivoc 2001, 1:17-54.
17. Sanchez B, Bautista J: Effects of furfural and 5-hydroxymethylfurfrual on the fermentation of Saccharomyces cerevisiae and biomass production from Candida uilliermondii. Enzyme Microb Technol 1988, 10:315-318.

18. Khan $Q$, Hadi S: Inactivation and repair of bacteriophage lambda by furfural. Biochem Mol Biol Int 1994, 32:379-385.

19. Modig T, Liden G, Taherzadeh M: Inhibition effects of furfural on alcohol dehydrogenase, aldehyde dehydrogenase, and pyruvate dehydrogenase. Biochem J 2002, 363:769-776.

20. Allen SA, Clark W, McCaffery JM, Cai Z, Lanctot A, Slininger PJ, Liu ZL, Gorsich SW: Furfural induces reactive oxygen species accumulation and cellular damage in Saccharomyces cerevisiae. Biotechnol Biofuels 2010, 3:2.

21. Morimoto S, Murakami M: Studies on fermentation products from aldehyde by microorganisms: the fermentative production of furfural alcohol from furfural by yeast (part I). J Ferment Technol 1967, 45:442-446.

22. Villa GP, Bartroli R, Lopez R, Guerra M, Enrique M, Penas M, Rodriquez E, Redondo D, Jglesias I, Diaz M: Microbial transformation of furfural to furfuryl alcohol by Saccharomyces cerevisiae. Acta Biotechnol 1992, 12:509-512.

23. Liu ZL: Genomic adaptation of ethanologenic yeast to biomass conversion inhibitors. Appl Microbiol Biotechnol 2006, 73:27-36.

24. Liu ZL, Slininger PJ, Dien BS, Berhow MA, Kurtzman CP, Gorsich SW: Adaptive response of yeasts to furfural and 5 -hydroxymethylfurfural and new chemical evidence for HMF conversion to 2,5-bishydroxymethylfuran. J Ind Microbiol Biotechnol 2004, 31:345-352.

25. Taherzadeh MJ, Gustafsson L, Niklasson C, Liden G: Physiological effects of 5-hydroxymethylfurfural on Saccharomyces cerevisiae. Appl Microbiol Biotechnol 2000, 53:701-708.

26. Liu ZL, Moon J, Andersh AJ, Slininger PJ, Weber S: Multiple gene mediated $\mathrm{NAD}(\mathrm{P}) \mathrm{H}$-dependent aldehyde reduction is a mechanism of in situ detoxification of furfural and HMF by ethanologenic yeast Saccharomyces cerevisiae. Appl Microbiol Biotechnol 2008, 81:743-753.

27. Liu ZL, Moon J: A novel NADPH-dependent aldehyde reductase gene from Saccharomyces cerevisiae NRRL Y-12632 involved in the detoxification of aldehyde inhibitors derived from lignocellulosic biomass conversion. Gene 2009, 446:1-10.

28. Liu ZL, Slininger PJ, Gorsich SW: Enhanced biotransformation of furfural and 5-hydroxy methylfurfural by newly developed ethanologenic yeast strains. Appl Biochem Biotechnol 2005, 121-124:451-460.

29. Liu ZL, Ma M, Song M: Evolutionarily engineered ethanologenic yeast detoxifies lignocellulosic biomass conversion inhibitors by reprogrammed pathways. Mol Genet Genomics 2009, 282:233-244.

30. Boorsma A, Foat BC, Vis D, Klis F, Bussemaker HJ: T-profiler: scoring the activity of predefined groups of genes using gene expression data. Nucl Acids Res 2005, 33:W592-W595.

31. Teixeira MC, Monteiro $P$, Jain $P$, Tenreiro $S$, Fernandes AR, Mira NP, Alenquer M, Freitas AT, Oliveira AL, Sá-Correia I: The YEASTRACT database: a tool for the analysis of transcription regulatory associations in Saccharomyces cerevisiae. Nucl Acids Res 2006, 34:D446-D451.

32. Lee TI, Rinaldi NJ, Robert F, Odom DT, Bar-Joseph Z, Gerber GK, Hannett NM, Harbison CT, Thompson CM, Simon I, Zeitlinger J, Jennings EG, Murray HL, Gordon DB, Ren B, Wyrick JJ, Tagne JB, Volkert TL,

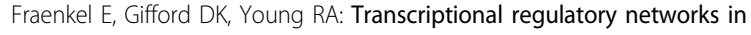
Saccharomyces cerevisiae. Science 2002, 298:799-804.

33. Harbison CT, Gordon DB, Lee TI, Rinaldi NJ, Macisaac KD, Danford TW, Hannett NM, Tagne JB, Reynolds DB, Yoo J, Jennings EG, Zeitlinger J, Pokholok DK, Kellis M, Rolfe PA, Takusagawa KT, Lander ES, Gifford DK, Fraenkel E, Young RA: Transcriptional regulatory code of a eukaryotic genome. Nature 2004, 31:99-104.

34. Hahn JS, Neef DW, Thiele DJ: A stress regulatory network for co-ordinated activation of proteasome expression mediated by yeast heat shock transcription factor. Mol Microbiol 2006, 60:240-251.

35. Larochelle M, Drouin S, Robert F, Turcotte B: Oxidative stress-activated zinc cluster protein $\mathrm{Stb5}$ has dual activator/repressor functions required for pentose phosphate pathway regulation and NADPH production. Mol Cell Biol 2006, 26:6690-6701.

36. Workman $C T$, Mak HC, McCuine S, Tagne JB, Agarwal M, Ozier O, Begley TJ, Samson LD, Ideker T: A systems approach to mapping DNA damage response pathways. Science 2006, 312:1054-1059.

37. Salin H, Fardeau V, Piccini E, Lelandais G, Tanty V, Lemoine S, Jacq C, Devaux F: Structure and properties of transcriptional networks driving selenite stress response in yeasts. BMC Genomics 2008, 9:333. 
38. Haugen AC, Kelley R, Collins JB, Tucker CJ, Deng C, Afshari CA, Brown JM, Ideker T, Van Houten B: Integrating phenotypic and expression profiles to map arsenic-response networks. Genome Biol 2004, 5:R95.

39. Fernandes $L$, Rodrigues-Pousada C, Struhl K: Yap, a novel family of eight bZIP proteins in Saccharomyces cerevisiae with distinct biological functions. Mol Cell Biol 1997, 17:6982-6993.

40. Nguyên DT, Alarco AM, Raymond M: Multiple Yap1p-binding sites mediate induction of the yeast major facilitator FLR1 gene in response to drugs, oxidants, and alkylating agents. J Biol Chem 2001, 276:1138-1145.

41. Dubacq C, Chevalier A, Courbeyrette R, Petat C, Gidrol X, Mann C: Role of the iron mobilization and oxidative stress regulons in the genomic response of yeast to hydroxyurea. Mol Genet Genomics 2006, 275:114-124.

42. Mamnun YM, Pandjaitan R, Mahé Y, Delahodde A, Kuchler K: The yeast zinc finger regulators $\mathrm{Pdr} 1 \mathrm{p}$ and $\mathrm{Pdr} 3 \mathrm{p}$ control pleiotropic drug resistance (PDR) as homo- and heterodimers in vivo. Mol Microbiol 2002, 46:1429-1440.

43. Moye-Rowley WS: Transcriptional control of multidrug resistance in the yeast Saccharomyces. Prog Nucleic Acid Res Mol Biol 2003, 73:251-279.

44. Jungwirth $H$, Kuchler $K$ : Yeast $A B C$ transporters - a tale of sex, stress, drugs, and aging. FEBS Lett 2006, 580:1131-1138.

45. MacPherson S, Larochelle M, Turcotte B: A fungal family of transcriptional regulators: the zinc cluster proteins. Microbiol Mol Biol Rev 2006, 70:583-604.

46. Hellauer $\mathrm{K}$, Rochon MH, Turcotte $\mathrm{B}$ : A novel DNA binding motif for yeast zinc cluster proteins: the Leu3p and Pdr3p transcriptional activators recognize everted repeats. Mol Cell Biol 1996, 16:6096-6102.

47. Katzmann DJ, Hallstrom TC, Voet M, Wysock W, Golin J, Volckaert G, MoyleRowley WS: Expression of an ATP-binding cassette transporter-encoding gene (YOR1) is required for oligomycin resistance in Saccharomyces cerevisiae. Mol Cell Biol 1995, 15:6875-6883.

48. Mahé $Y$, Lemoine $Y$, Kuchler K: The ATP binding cassette transporters Pdr5 and Snq2 of Saccharomyces cerevisiae can mediate transport of steroids in vivo. J Biol Chem 1996, 271:25167-25172.

49. Wolfger $H$, Mahé $Y$, Parle-McDermott A, Delahodde A, Kuchler K: The yeast ATP binding cassette $(\mathrm{ABC})$ proteins PDR10 and PDR15 are novel targets for the Pdr1 and Pdr3 transcriptional regulators. FEBS Lett 1997, 418:269-274

50. DeRisi J, van den Hazel B, Marc P, Balzi E, Brown P, Jacq C, Goffeau A: Genome microarray analysis of transcriptional activation in multidrug resistance yeast mutants. FEBS Lett 2000, 470:156-160.

51. Onda M, Ota K, Chiba T, Sakaki Y, Ito T: Analysis of gene network regulating yeast multidrug resistance by artificial activation of transcription factors: involvement of Pdr3 in salt tolerance. Gene 2004, 332:51-59.

52. Alenquer M, Tenreiro S, Sá-Correia I: Adaptive response to the antimalarial drug artesunate in yeast involves Pdr1p/Pdr3p-mediated transcriptional activation of the resistance determinants TPO1and PDR5. FEMS Yeast Res 2006, 6:1130-1139.

53. Zhu Y, Xiao W: Pdr3 is required for DNA damage induction of MAG1 and DDI1 via a bi-directional promoter element. Nucl Acids Res 2004, 32:5066-5075.

54. Kihara A, Igarashi Y: Cross talk between sphingolipids and glycerophospholipids in the establishment of plasma membrane asymmetry. Mol Biol Cell 2004, 15:4949-4959.

55. Delahodde A, Delaveau T, Jacq C: Positive autoregulation of the yeast transcription factor Pdr3p, which is involved in control of drug resistance. Mol Cell Biol 1995, 15:4043-4051.

56. Mannhaupt G, Schnall R, Karpov V, Vetter I, and Feldmann H: Rpn4p acts as a transcription factor by binding to PACE, a nonamer box found upstream of 26 S proteasomal and other genes in yeast. FEBS Lett 1999, 450:27-34

57. Xie $Y$, Varshavsky A: RPN4 is a ligand, substrate, and transcriptional regulator of the $26 \mathrm{~S}$ proteasome: a negative feedback circuit. Proc Natl Acad Sci USA 2001, 98:3056-3061.

58. Ferguson SB, Anderson ES, Harshaw RB, Thate T, Craig NL, Nelson HC: Protein kinase $A$ regulates constitutive expression of small heat-shock genes in an Msn2/4p-independent and Hsf1p-dependent manner in Saccharomyces cerevisiae. Genetics 2005, 169:1203-1214.

59. De Rijcke M, Seneca S, Punyammalee B, Glansdorff N, Crabeel M: Characterization of the DNA target site for the yeast ARGR regulatory complex, a sequence able to mediate repression or induction by arginine. Mol Cell Biol 1992, 12:68-81.

60. Natarajan K, Meyer MR, Jackson BM, Slade D, Roberts C, Hinnebusch AG, Marton MJ: Transcriptional profiling shows that Gcn4p is a master regulator of gene expression during amino acid starvation in yeast. $\mathrm{Mol}$ Cell Biol 2001, 21:4347-4368.

61. Petersson A, Almeida JR, Modig T, Karhumaa K, Hahn-Hägerdal B, GorwaGrauslund MF, Lidén G: A 5-hydroxymethyl furfural reducing enzyme encoded by the Saccharomyces cerevisiae ADH6 gene conveys HMF tolerance. Yeast 2006, 23:455-464

62. Nilsson A, Gorwa-Grauslund MF, Hahn-Hägerdal B, Lidén G: Cofactor dependence in furan reduction by Saccharomyces cerevisiae in fermentation of acid-hydrolyzed lignocellulose. Appl Environ Microbiol 2005, 71:7866-7871.

63. Heer D, Heine D, Sauer U: Resistance of Saccharomyces cerevisiae to high concentrations of furfural is based on NADPH-dependent reduction by at least two oxireductases. Appl Environ Microbiol 2009, 75:7631-7638.

64. Alriksson B, Horváth IS, Jönsson LJ: Overexpression of Saccharomyces cerevisiae transcription factor and multidrug resistance genes conveys enhanced resistance to lignocellulose-derived fermentation inhibitors. Process Biochem 2010, 45:264-271

65. Gorsich SW, Dien BS, Nichols NN, Slininger PJ, Liu ZL, Skory CD: Tolerance to furfural-induced stress is associated with pentose phosphate pathway genes ZWF1, GND1, RPE1, and TKL1 in Saccharomyces cerevisiae. Appl Microbiol Biotechnol 2006, 71:339-349.

66. Kuge $\mathrm{S}$, Jones $\mathrm{N}$ : YAP1 dependent activation of TRX2 is essential for the response of Saccharomyces cerevisiae to oxidative stress by hydroperoxides. EMBO J 1994, 13:655-664.

67. Morgan BA, Banks GR, Toone WM, Raitt D, Kuge S, Johnston LH: The Skn7 response regulator controls gene expression in the oxidative stress response of the budding yeast Saccharomyces cerevisiae. EMBO J 1997, 16:1035-1044

68. Lee J, Godon C, Lagniel G, Spector D, Garin J, Labarre J, Toledano MB: Yap1 and Skn7 control two specialized oxidative stress response regulons in yeast. J Biol Chem 1999, 274:16040-16046.

69. Tan K, Feizi H, Luo C, Fan SH, Ravasi T, Ideker TG: A systems approach to delineate functions of paralogous transcription factors: role of the Yap family in the DNA damage response. Proc Natl Acad Sci USA 2008, 105:2934-2939.

70. Tomitori H, Kashiwagi K, Asakawa T, Kakinuma Y, Michael AJ, Igarashi K: Multiple polyamine transport systems on the vacuolar membrane in yeast. Biochem J 2001, 353:681-688

71. Teixeira MC, Sá-Correia I: Saccharomyces cerevisiae resistance to chlorinated phenoxyacetic acid herbicides involves Pdr1p-mediated transcriptional activation of TPO1 and PDR5 genes. Biochem Biophys Res Commun 2002, 292:530-537.

72. Miura S, Zou W, Ueda M, Tanaka A: Screening of genes involved in isooctane tolerance in Saccharomyces cerevisiae by using mRNA differential display. Appl Environ Microbiol 2000, 66:4883-4889.

73. Ghosh AK, Ramakrishnan G, Rajasekharan R: YLR099C (ICT1) encodes a soluble Acyl-CoA-dependent lysophosphatidic acid acyltransferase responsible for enhanced phospholipid synthesis on organic solvent stress in Saccharomyces cerevisiae. J Biol Chem 2008, 283:9768-9775.

74. Chen J, Derfler B, Samson L: Saccharomyces cerevisiae 3-methyladenine DNA glycosylase has homology to the AlkA glycosylase of $E$. coli and is induced in response to DNA alkylation damage. EMBO J 1990, 9:4569-4575.

75. Fu Y, Pastushok $L$, Xiao W: DNA damage-induced gene expression in Saccharomyces cerevisiae. FEMS Microbiol Rev 2008, 32:908-926.

76. Clarke DJ, Mondesert G, Segal M, Bertolaet BL, Jensen S, Wolff M, Henze M, Reed SI: Dosage suppressors of $p d s 1$ implicate ubiquitin-associated domains in checkpoint control. Mol Cell Biol 2001, 21:1997-2007.

77. Reed SH, You Z, Friedberg EC: The yeast RAD7 and RAD16 genes are required for postincision events during nucleotide excision repair. In vitro and in vivo studies with rad7 and rad16 mutants and purification of a Rad7/Rad16-containing protein complex. J Biol Chem 1998, 273:29481-29488.

78. Song M, Ouyang Z, Liu ZL: Discrete dynamic system modeling for gene regulatory networks of HMF tolerance for ethanologenic yeast. IET Sys Biology 2009, 3:203-218. 
79. Song M, Liu ZL: A linear discrete dynamic system model for temporal gene interaction and regulatory network influence in response to bioethanol conversion inhibitor HMF for ethanologenic yeast. Lect Notes Bioinfomatics 2007, 4532:77-95.

80. Goldberg AL: Protein degradation and protection against misfolded or damaged proteins. Nature 2003, 426:895-899.

81. Burnie JP, Carter TL, Hodgetts SJ, Matthews RC: Fungal heat-shock proteins in human disease. FEMS Microbiol Rev 2006, 30:53-88.

82. Wang $X, X u H, H a$ SW, Ju D, Xie Y: Proteasomal degradation of Rpn4 in Saccharomyces cerevisiae is critical for cell viability under stressed conditions. Genetics 2010, 184:335-342.

83. Wang $X, X u H$, Ju D, Xie Y: Disruption of Rpn4-induced proteasome expression in Saccharomyces cerevisiae reduces cell viability under stressed conditions. Genetics 2008, 180:1945-1953.

84. Glickman MH, Ciechanover A: The ubiquitin proteasome proteolytic pathway: destruction for the sake of construction. Physiol Rev 2002, 82:373-428.

85. Winzeler EA, Shoemaker DD, Astromoff A, Liang $H$, Anderson $K$, Andre B, Bangham R, Benito R, Boeke JD, Bussey H, Chu AM, Connelly C, Davis K, Dietrich F, Dow SW, El Bakkoury M, Foury F, Friend SH, Gentalen E, Giaever G, Hegemann JH, Jones T, Laub M, Liao H, Liebundguth N, Lockhart DJ, Lucau-Danila A, Lussier M, M'Rabet N, Menard P, Mittmann M, Pai C, Rebischung C, Revuelta JL, Riles L, Roberts CJ, Ross-MacDonald P, Scherens B, Snyder M, Sookhai-Mahadeo S, Storms RK, Véronneau S, Voet M, Volckaert G, Ward TR, Wysocki R, Yen GS, Yu K, Zimmermann K, Philippsen P, Johnston M, Davis RW: Functional characterization of the $S$. cerevisiae genome by gene deletion and parallel analysis. Science 1999, 285:901-906

86. Liu ZL, Slininger PJ: Universal external RNA controls for microbial gene expression analysis using microarray and qRT-PCR. J Microbiol Methods 2007, 68:486-496.

87. Hegde P, Qi R, Abernathy K, Gay C, Dharap S, Gaspard R, Earle-Hughes J, Snesrud $E$, Lee N, Quackenbush J: A concise guide to CDNA microarray analysis. BioTechniques 2000, 29:548-562.

88. Ashburner M, Ball CA, Blake JA, Botstein D, Butler H, Cherry JM, Davis AP, Dolinski K, Dwight SS, Eppig JT, Harris MA, Hill DP, Issel-Tarver L, Kasarskis A, Lewis S, Matese JC, Richardson JE, Ringwald M, Rubin GM, Sherlock G: Gene ontology: tool for the unification of biology. Nat Genet 2000, 25:25-29.

89. Ruepp A, Zollner A, Maier D, Albermann K, Hani J, Mokrejs M, Tetko I, Güldener U, Mannhaupt G, Münsterkötter M, Mewes HW: The FunCat, a functional annotation scheme for systematic classification of proteins from whole genomes. Nucl Acids Res 2004, 32:5539-5545.

90. Liu ZL, Palmquist DE, Ma M, Liu J, Alexander NJ: Application of a master equation for quantitative mRNA analysis using qRT-PCR. J Biotechnol 2009, 143:10-16.

doi:10.1186/1471-2164-11-660

Cite this article as: Ma and Liu: Comparative transcriptome profiling analyses during the lag phase uncover YAP1, PDR1, PDR3, RPN4, and HSF1 as key regulatory genes in genomic adaptation to the lignocellulose derived inhibitor HMF for Saccharomyces cerevisiae. BMC Genomics 2010 11:660.

\section{Submit your next manuscript to BioMed Central and take full advantage of:}

- Convenient online submission

- Thorough peer review

- No space constraints or color figure charges

- Immediate publication on acceptance

- Inclusion in PubMed, CAS, Scopus and Google Scholar

- Research which is freely available for redistribution

Submit your manuscript at www.biomedcentral.com/submit
Biomed Central 